\title{
Laboreal
}

Volume $12 \mathrm{~N}^{\circ} 2$ | 2016

Equipamentos de Proteção Individual II

\section{Gestión del cambio en las organizaciones: efectos sobre la actividad y las personas}

A gestão da mudança nas organizações: efeitos sobre a atividade e as pessoas La gestion du changement dans les organisations: effets sur l'activité et les personnes

Managing change in organizations: effects on activity and people

\section{Carlos Díaz Canepa}

\section{OpenEdition}

\section{Journals}

Edición electrónica

URL: http://journals.openedition.org/laboreal/2314

DOI: $10.4000 /$ laboreal.2314

ISSN: 1646-5237

\section{Editor}

Universidade do Porto

\section{Referencia electrónica}

Carlos Díaz Canepa, « Gestión del cambio en las organizaciones: efectos sobre la actividad y las personas », Laboreal [En línea], Volume 12 №2 | 2016, Publicado el 01 diciembre 2016, consultado el 10 diciembre 2020. URL : http://journals.openedition.org/laboreal/2314 ; DOI : https://doi.org/ 10.4000/laboreal.2314

Este documento fue generado automáticamente el 10 diciembre 2020.

\section{(c) (†) \$)}

Laboreal está licenciado com uma Licença Creative Commons - Atribuição-NãoComercial 4.0 Internacional. 


\section{Gestión del cambio en las organizaciones: efectos sobre la actividad y las personas}

A gestão da mudança nas organizações: efeitos sobre a atividade e as pessoas

La gestion du changement dans les organisations: effets sur l'activité et les

personnes

Managing change in organizations: effects on activity and people

Carlos Díaz Canepa

\section{NOTA DEL EDITOR}

http://dx.doi.org/10.15667/laborealxii0216cdc

Manuscrito recibido en: septiembre/2015

Aceptado tras peritaje: mayo/2016

\section{Introducción}

A pesar de la idea que, desde fines del siglo XIX y durante gran parte del siglo XX, sustentó el desarrollo de los grandes sistemas burocráticos y que aspiraba que las organizaciones debían comportarse como máquinas basadas en rutinas que asegurasen la reproducción de procesos, roles y su estabilidad en el tiempo (Weber, 1964), para nadie resulta ya sorpresivo ni novedoso, el hecho que las organizaciones cambian en variadas formas y en mérito a causas diversas a través del tiempo. Tampoco resulta sorpresivo constatar que tales cambios afecten en variadas formas el marco en el que se desarrolla la actividad que las personas despliegan al interior de las organizaciones $y$, por ende, sus situaciones personales, sus percepciones respecto a la organización, así como las formas y contenidos de la actividad efectiva que realizan. 
2 Consistentemente, las ciencias sociales han prestado desde hace décadas un significativo interés a los procesos de cambio organizacional y el impacto de estos cambios sobre las personas y sus comportamientos, abordando con distintos énfasis las distintas perspectivas y variados tópicos relacionados, de modo tal que la literatura en torno a los procesos de cambio en las organizaciones es abundante, brindando el desarrollo de un nutrido arsenal conceptual y casuístico. Cabe no obstante destacar que, por lo general, la literatura en este campo hace énfasis en que los cambios organizacionales, suponen ciertamente la aparición de nuevos escenarios y tienden preferencialmente a referirse a efectos en el plano de las actitudes, emociones y resistencias frente al cambio (Dent \& Galloway, 1999; Kiefer, 2005; Strebel, 2005; Devos, Buelens \& Bouckenooghe, 2007; Fugate, Kinicki \& Prussia, 2008; Smollan, 2011), el rol del liderazgo (Denis, Lamothe, \& Langley, 1996; Kotter, 2005; Boga \& Ensari, 2009) o las perspectivas analíticas (Golembiewski, 1986; van de Ven, \& Poole, 1995; Tsoukas \& Chia, 2002; Pina \& Vieira, 2003). En contraste, poco se han considerado los efectos que los cambios en la organización acarrean sobre la actividad que despliegan las personas para el logro de sus objetivos. Incluso si consideramos la muy interesante revisión en relación a las teorías del cambio desarrollada por Demers (2007), en la que se incluye a autores ligados a la teoría de la actividad, tales como Engeström y Miettinen, esta autora lo hace desde la perspectiva de referir a la influencia de la actividad sobre los cambios, pero no aborda los efectos que los cambios producen sobre la actividad de los miembros de la organización.

3 En este artículo, se revisarán estos tópicos. Se introducirán elementos de análisis sobre los procesos de cambio y los alcances que los cambios que acaecen en la organización, sobre sus sistemas, herramientas y procesos tienen sobre la actividad de las personas. Con este propósito, se ha procedido a seleccionar las fuentes en función de su pertinencia, buscando cubrir en lo posible, la gama de enfoques y tópicos que se presentan en la literatura en torno al cambio organizacional (ver entre estos, por ej., van de Ven et al. 1995; Stensaker, Falkenberg, Meyer \& Hagueng, 2002; Tsoukas et al., 2002; Demers, 2007 (op. cit.); Burke, 2008). Complementariamente, con el objeto de situar la relación entre cambio organizacional y actividad, así como para contribuir a la integración del análisis de la actividad humana, en tanto que dimensión crítica a considerar en los procesos de cambio organizacional, es que aquí abordaremos dicha relación apoyándonos en las conceptualizaciones desarrolladas en la ergonomía contemporánea en relación a este último concepto (ver entre estos, por ej., Rabardel, 1995; Bedny \& Meister,1997; Erickson y Schultz, 1997; Engeström,1999; Clot, 1999; Thereau, 2001; Kuuti, 2001; Leplat, 2004).

4 Para estos efectos presentaremos primero, una breve argumentación en torno al rol mediador que las componentes organizacionales y tecnológicas tienen sobre la actividad, y como el cambio de estas componentes la afectan. Luego se presentan esquemáticamente, y sin pretender ser exhaustivos, diversas visiones que al día de hoy participan del debate sobre cambio organizacional, e intentaremos sintetizar algunos de los aspectos relevantes a considerar al momento de diagnosticar e intervenir en procesos de cambio en las organizaciones, tales como la resistencia al cambio, la cultura organizacional y otros. Por último, esbozaremos un enfoque que apunta a conciliar los afluentes provenientes, por una parte desde la gestión del cambio y, por otra, de las corrientes centradas en la actividad. A modo ilustrativo, citaremos muy someramente 
algunos antecedentes extraídos de algunas experiencias de cambio organizacional en Chile.

\section{La Organización y las Tecnologías como Mediadores de la Actividad}

Según Bedny et al. (1997, op. cit.), la actividad sería un proceso mediado socialmente, ya que primariamente se encontraría marcada por la división social del trabajo, así como por los procesos de intercambio que sedimentan las relaciones entre individuos y comunidades en sociedad. Serían tales intercambios los que determinarían en buena medida las formas de la actualización de la actividad de las personas y los colectivos.

Desde esta perspectiva, cabe destacar que una premisa clave a tener en consideración es el hecho que las organizaciones son sistemas sociales y culturales cristalizados en un conjunto de prácticas, reglas, procesos y artefactos (Engeström, 1999 (op.cit.); Miettinen y Virkkunen, 2005). En ellas se juegan diversas dinámicas de corte pragmático y relacionales, así como de juegos de influencia individuales y grupales. Tales dinámicas, enmarcadas en un escenario situado (Rogoff y Lave, 2000), van a ir definiendo en buena medida los contenidos, orientaciones y formas que adquirirían las acciones y metas concretas hacia las que estas acciones se dirigirían. En ese mismo contexto, por la propia dialéctica en la que se desenvuelve la actividad, se sentarían las bases para la aparición de nuevas prácticas, conducentes en muchos casos a cambios, donde la intencionalidad de los agentes, lo emergente y lo azaroso se imbricarían de un modo que no resulta siempre obvio dilucidar (Engeström, 1999 (Ibid); Miettinen y Virkkunen, 2005, (Ibid.)).

7 En un sentido más específico, una distinción básica para entender el concepto de actividad, es la que establece Leplat (2004, op. cit.), quien señala que tarea y actividad no serían asimilables, pues la tarea respondería al objetivo prescrito por la organización y las condiciones definidas por esta para su realización, mientras que la actividad sería aquello que los operadores humanos realizarían efectivamente para llevar a cabo la tarea, lidiando con exigencias internas, propias al sujeto, así como a las condiciones contextuales en las que la actividad se realiza. Así, según este autor, la relación entre ambas dimensiones del trabajo, lo prescrito y lo efectivo, estaría al centro de un análisis comprensivo del trabajo humano. De este modo, la definición de la tarea, sería un referente externo ineludible en la construcción de la actividad que las personas despliegan en situación de trabajo.

8 Matizando esta perspectiva, se ha hecho igualmente hincapié en el carácter histórico y social de la generación de las prescripciones, las que de algún modo serían reflejo cristalizado provisorio de la propia actividad humana, pues sería resultante del juego de contradicciones y acuerdos entre los distintos agentes que participarían de los escenarios de trabajo, y por lo tanto estas prescripciones no serían externas ni marginales a la propia actividad, sino que parte inherente de ella (Clot, 1999, op. cit.).

9 En contraste con estas visiones, también se ha planteado que los reglamentos y normas establecidos por las organizaciones para regular los comportamientos de sus miembros, no serían necesariamente respetadas tal como fueron prescritas, aunque los miembros de la organización no podrían tampoco comportarse exactamente como lo desean (Rodríguez,1992). Incluso se ha enfatizado la naturaleza subjetiva que subyacería a la 
deriva de la actividad que las personas desarrollan, generando formas particulares de apropiación y de acoplamientos estructurales con el entorno, construyendo el sentido que en definitiva adquirirían las exigencias para las personas. Razón por la cual, según esta perspectiva, las prescripciones organizacionales jugarían sólo un rol marginal en el desarrollo de la actividad (Thereau, 2001, op.cit.).

Independientemente de las discrepancias que son posibles de identificar entre las distintas visiones, matices y énfasis respecto del rol que juegan los factores prescriptivos en el desarrollo de la actividad, lo que puede relevarse como factor común, es el hecho del carácter situado y constructivo que la define, ya sea con énfasis en la influencia del marco prescriptivo referencial externo otorgado por la tarea, en la dinámica de acoplamiento con el entorno de acción, o en la dinámica de los agentes sociales que participan de los escenarios de trabajo. Más aun, es posible deducir que la naturaleza situada de la actividad se sostendría en diversos factores de carácter objetivo e interpretativo.

11 Complementariamente, autores tales como Nathanael y Marmaras (2008) han hecho énfasis en el rol de los artefactos técnicos en la estructuración de la actividad humana, y señalan que las prácticas y los nexos entre ellas, estarían mediados por artefactos de diversa índole. Del mismo modo, Kuutti (2001, op.cit.) hace hincapié en que la actividad estaría mediada por efectos de las características de herramientas sobre las que se apoya su despliegue. Este autor señala que una actividad siempre contiene diversos artefactos: instrumentos, señales, procedimientos, maquinas, métodos, leyes, formas de organización del trabajo, etc., los que estarían jugando un rol mediador entre los distintos planos de la actividad. Más aun, indica, los propios artefactos serían resultado del desarrollo de la actividad humana a lo largo de su historia y transmitidos culturalmente. Según Rabardel (1995, op. cit.), tales herramientas poseerían a la vez un carácter simbólico y material, pues al interior de sus formas objetivadas, canalizarían diversos significados inscritos en su estructura desde su diseño, incorporando en ellos prácticas sociales de diverso orden, tanto pragmáticas, como aquellas que reflejarían la división social del trabajo. Estos significados intencionarían el sentido de la actividad a desarrollar por las personas, e influirían en su estructura. De este modo, en el plano pragmático, Rabardel señala que las herramientas "propondrían" a priori determinados propósitos de uso. Así, por ejemplo, un martillo tendría por propósito inscrito el de permitir clavar clavos y ciertas modalidades de uso prefiguradas, ya que el uso del martillo estaría "sugerido" por efectos de contar con una componente dura, destinada a golpear la cabeza del clavo y una componente de soporte, destinada a facilitar la prensión y aplicación de fuerza por parte de su usuario. De este modo, dichos significados inscritos incidirían en la articulación de la actividad orientada a metas, definiendo formas preestablecidas para la realización de la acción.

De igual manera, los diversos instrumentos con los que operaría un colectivo al interior de una organización, incidirían en variados grados en la diferenciación de roles y status entre sus miembros, definiendo por ejemplo, distintos derechos de acceso, ingreso y modificación de la información organizacional, así como en las capacidades de acción al interior del quehacer organizacional. Particularmente relevante en este aspecto, son sin duda los impactos derivados de la masificación de herramientas TIC's en los escenarios organizacionales, las que no sólo implican requerimientos de aprendizaje al uso de dichas herramientas, sino que igualmente suponen esfuerzos para aprender y 
apropiarse de nuevas formas de gestión de la información, proceso que redundaría en efectos sobre el ordenamiento social de la organización (Leonardi, 2007).

Desde estas perspectivas, la influencia sobre la actividad que presentarían las prescripciones organizacionales y los instrumentos con que cuenta la organización derivaría del carácter referencial y mediador que estos factores jugarían (figura 1). Por una parte, las prescripciones y las herramientas disponibles, operarían como marco y medio para la realización de los propósitos de la actividad, mientras que por otro, mediatizando y delimitando dicha actividad, por efectos de las características, posibilidades y alcances que estos factores ofrecerían (Díaz Canepa, 2005).

Figura 1: Esquema de mediación organizacional e instrumental de la actividad (Díaz Canepa, 2005, op. cit.)

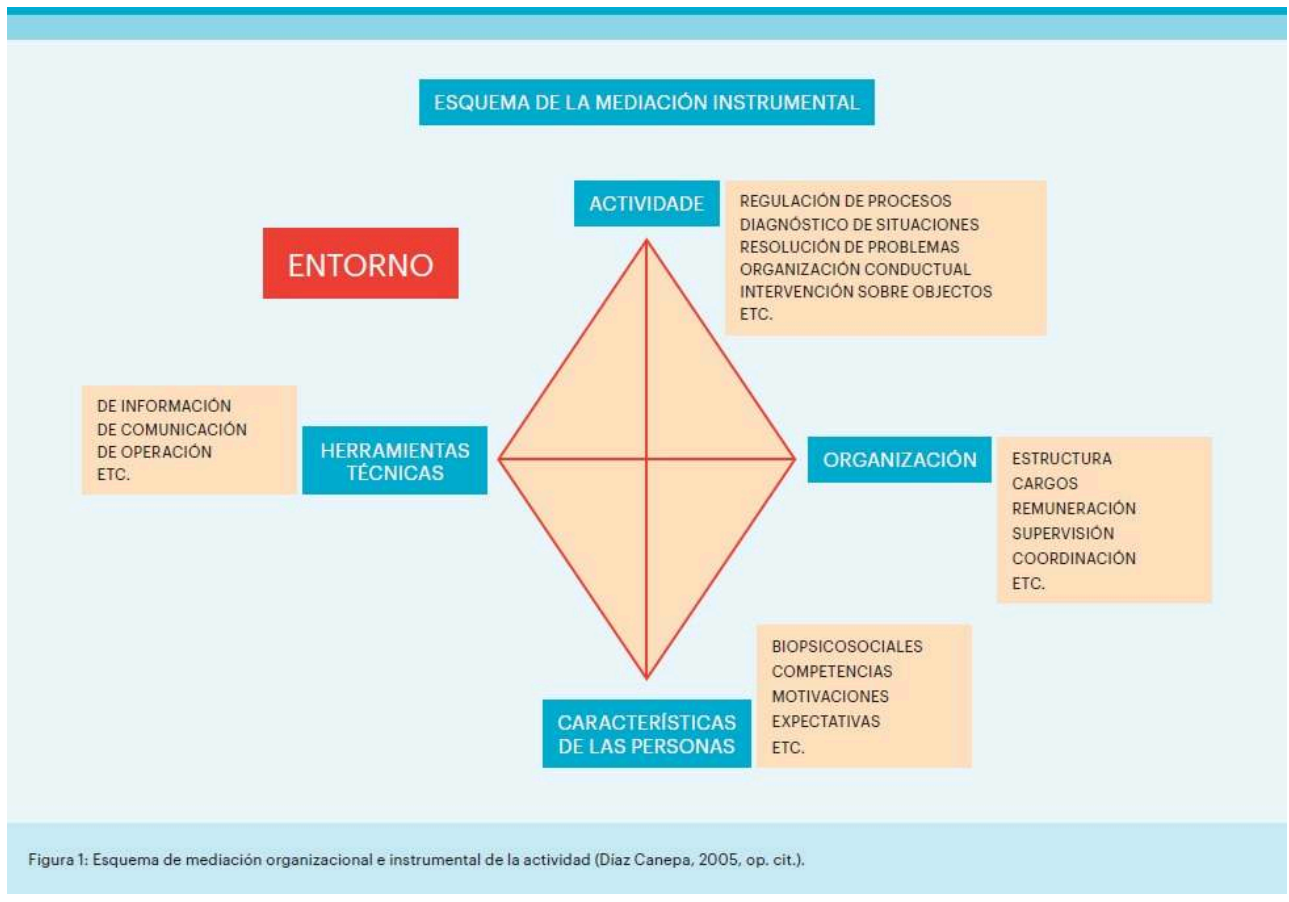

Así, si bien las prescripciones abren un rango de posibilidades de acción al consignar objetivos, atribuciones y reglas de operación, a su vez, acotan el ámbito de acción por efectos de la definición de una posición en la trama jerárquica, un lugar y metas fijadas en un campo funcional determinado, entre otras restricciones. Del mismo modo, las características de los instrumentos y herramientas con las cuales las personas desarrollan su actividad, el grado de heterogeneidad que presentan, sus niveles de integración y cobertura, su complejidad tecnológica, sus grados de afordancia [1], su disponibilidad y confiabilidad, etc., serían factores que influirían tanto en la naturaleza, como en la forma que adquiriría la actividad de las personas.

Extensivamente, características tales como el tamaño de la organización, su giro productivo o de servicios, su carácter urbano o rural, su historia y cultura, su tipo de estructura y definición de cargos, su estilo de supervisión, de comunicación y coordinación, su estructura de remuneraciones, su estilo de gestión, etc., serían ciertamente factores que incidirían, al igual que las prescripciones formales, de una manera $u$ otra en el cómo las personas organizan y despliegan su actividad. 
17 Sin embargo, cabe destacar que tales dinámicas no sólo dependerían de los factores arriba mencionados, sino que se irían igualmente construyendo a la sazón de la búsqueda de un equilibrio sostenible entre las exigencias asociadas tanto al logro de metas, el cumplimiento de las prescripciones laborales e instrumentales, así como de aquellas derivadas de las propias características, capacidades y necesidades personales y colectivas de los miembros de la organización, llevándolos a menudo a redefinir o a completar lo prescrito (Terssac de, 1990 y de Terssac de \& Chabaud, 1990; Leplat, 1997). Tales procesos tienden a derivar en la generación de particulares formas de uso de las herramientas que las personas disponen, desarrollando modalidades sustitutas o complementarias a las funcionalidades que estas herramientas cuentan (Díaz Canepa, 2008a). Estas dinámicas darían pie al desarrollo de formas emergentes de despliegue de la actividad, las que a su vez incidirían dialécticamente en la configuración de referenciales organizacionales e instrumentales efectivos, distintos de los prescritos.

Erickson, et al. (1997, op. cit.) ponen el acento en la actividad humana en tanto que configuradora de contextos. Para estos efectos, plantean una serie de preguntas relevantes: ¿Qué hacen las personas, dónde y cuándo lo hacen? Serían preguntas claves para entender de qué contexto se trata. ¿Cómo afecta el contexto la actividad de las personas? ¿Cómo hacen las personas para identificar en qué contexto se encuentran? ¿Cuándo cambia un contexto? Con base a este tipo de interrogantes, estos autores señalan que el contexto sería entonces, más que el escenario físico al interior del cual se encuentran las personas o más que la combinación de personas y roles que participan de una situación determinada, ya que igualmente respondería al carácter social e interaccional, resultante tanto de las definiciones compartidas y ratificadas mutuamente entre los participantes a dicha situación, así como de las acciones sociales que estos actualicen en referencia a tales definiciones.

Siguiendo esta lógica, sería posible señalar que los contextos organizacionales e instrumentales, no serían entonces dados gracias a la sola articulación de las variables objetivas que poseerían las situaciones de trabajo, sino que estos serían fenómenos emergentes en los que los factores físicos y sociales se conjugarían en su producción por medio de la actividad de los actores.

En suma, si bien es posible afirmar que tanto la naturaleza, forma, distribución y modos de operar prescritos de la organización y de las tecnologías que las organizaciones disponen, marcan rangos de posibilidades y límites al quehacer de las personas, incidiendo en las dinámicas y representaciones que las personas van desarrollando a través del tiempo en torno a su quehacer, a su vez estas características se irían dialécticamente modulando por las propias dinámicas de redefinición y completación que las personas despliegan por medio de su actividad (de Terssac, 1990).

21 De este modo, si es cierto que la actividad no se desprende de modo natural y automático de las características formales de las organizaciones y sus herramientas, también es cierto que los cambios en estas componentes pueden no obstante poner en tensión el equilibrio circunstancial existente dentro de los sistemas de trabajo y traducirse en variados efectos sobre la actividad de las personas. Dichos cambios, bien orientados y conducidos, pueden eventualmente constituir un real beneficio para las organizaciones y las personas, mejorando las condiciones de acoplamiento entre estos factores, las personas y su actividad. Sin embargo, una definición inadecuada de las formas de realización de estos cambios, pueden derivar en variadas problemáticas. 


\section{El Cambio Organizacional: Un Fenómeno Complejo}

22 De los distintos desarrollos teóricos revisados en torno a los procesos de cambio organizacional, así como de la casuística que consigna la literatura especializada, se puede desprender que los cambios en las organizaciones pueden responder a distintas causas, tomar diversas formas, situarse en distintas dimensiones y responder a distintas naturalezas, órdenes y lógicas de ocurrencia (Morel \& Ramanujam, 1999). Se entiende además que a menudo muchos tipos y formas de cambios, se presentan simultáneamente o por efectos de procesos en los que cambios en algún plano, conducen a cambios en diversos otros planos. Tales procesos pueden por lo demás, ser eventualmente coetáneos o encadenarse en el tiempo relacionados de forma causal, convergente o contradictoria, o simplemente de modo azaroso y sin relación aparente (Dooley \& Van de Ven, 1999). Tal riqueza y diversidad, hace no obstante que la sistematización del campo sea dificultosa y no permita fácilmente abarcarlo en su amplitud, ni dar orientaciones de acción que den cuenta satisfactoriamente de los requerimientos de la práctica organizacional en materia de gestión del cambio (Andrews, Cameron \& Harris, 2008).

23 Cabe destacar que a pesar de la existencia de variadas perspectivas en materia de cambio organizacional, en la práctica, por efectos de la inexistencia de un marco conceptual integrado entre aquellos que intervienen en este campo (Beer \& Nohria, 2000), tiende frecuentemente a predominar una mezcla de sentido común y de estereotipos sobre el comportamiento humano y de las organizaciones, dejando a menudo el tratamiento de los procesos de cambio a merced de las intuiciones y habilidades personales, de aquellos que dirigen o asesoran dichos procesos. Siendo esto así, el éxito o fracaso de los procesos de cambio, quedaría a menudo sujeto a factores y eventos fortuitos, de manera tal que, como lo señalan Beer et al. (2000, Ibid.), sólo un orden de un tercio de los proyectos de cambio, lograrían culminar exitosamente.

Pionero en el campo del cambio organizacional ha sido indudablemente Lewin (1947 a), quien ha marcado de manera significativa el desarrollo teórico y práctico en este ámbito, asentando una perspectiva de corte racional y teleológica con base a la cual los cambios organizacionales pueden ser definidos y conducidos por sus directivos. Sin embargo es de constatar que a pesar del carácter predominante de esta visión inaugurada por Lewin y cristalizada en la corriente denominada como Desarrollo Organizacional (DO), existe en este campo una interesante variedad de interpretaciones en el modo de entender el concepto de cambio. Así por ejemplo, si para Tsoukas et al. (2002, op.cit.), el cambio no sería un evento excepcional, o un hito referencial que marque un antes y un después, ni una corriente dirigida hacia un sentido o una meta, ya que este constituiría un proceso natural, un devenir de las cosas, marcado por la marea de las creencias y hábitos de acción, que los actores van produciendo a través de sus interacciones, de manera que estos puedan acomodar e integrar las nuevas experiencias que se van produciendo en la cotidianeidad. En contraste, otros autores, como por ejemplo Gladwell (2000), señalan por su parte que el cambio tiende a ser un evento abrupto, un quiebre en relación a lo previamente existente, gozando de una naturaleza contagiosa, ya que todo cambio induciría la emergencia de nuevos y sucesivos cambios, generándose a menudo un efecto mariposa, donde pequeños cambios pueden ser causa inicial de grandes efectos. 
Diversos autores han por su parte hecho énfasis en la distinción entre el carácter continuo o discontinuo de los cambios, asumiendo que de ello es posible desprender implicancias prácticas y efectos sobre las personas y las organizaciones (Bridges, 1991; Marks, 2003 y 2007).

Desde esta perspectiva, un cambio continuo apuntaría a la existencia de una trayectoria dirigida hacia un estado conocido con pasos ordenados, incrementales, asociados principalmente a procesos transformativos, de desarrollo y crecimiento, o de declinación y disminución de partes o del conjunto de la organización a través del tiempo. Un cambio discontinuo, por su parte referiría a una trayectoria dirigida hacia un estado desconocido, pudiendo involucrar diversos e interactivos cambios así como nuevos modos de pensar, organizarse y de realización de las actividades, e implicarían la ocurrencia de giros significativos del escenario organizacional, con cambios que se sucederían sin conexión necesaria o aparente en diversos planos de la organización.

Diversos otros autores tienden a referirse a los costos asociados al carácter continuo o discontinuo de los procesos de cambio. En este sentido por ejemplo, Weick \& Quinn (1999) y Marks (2003, Ibid.), señalan que los cambios discontinuos serían psicológicamente más costosos que los cambios continuos. Esto, por las mayores exigencias asociadas a las sucesivas adaptaciones que acompañarían a la discontinuidad de los procesos, así como por la eventual pérdida de sentido de congruencia que los saltos de un escenario de cambio a otro, acarrearían para los miembros de la organización. También se reporta que, mientras más cambios experimenten las personas en su trabajo, como es el caso de transiciones mayores, más se reportarían emociones negativas (Kiefer, 2005, op.cit.).

28 Esta distinción entre continuidad y discontinuidad puede ser sin embargo discutible. Así, por ejemplo, si se consideran las modalidades típicas de cambio organizacional en cascada, pensadas habitualmente como procesos de carácter continuo, en las que el desarrollo y alcances del cambio son definidos por el ápice organizacional para luego ser llevados a cabo sucesivamente por los niveles jerárquicos medios y posteriormente a los operacionales, podrían en contraste ser visualizados en tanto que procesos marcados por la discontinuidad. Esto, por el impacto fragmentador que tal modalidad de conducción del cambio tendería a producir en la organización, al implicar en distintas etapas a distintos actores ubicados en distintos niveles y contextos organizacionales de acción (Hannan, Polos, \& Caroll, 2003). Los distintos actores involucrados, contarían en consecuencia con distintos referentes interpretativos y pragmáticos del cambio a realizar, así como de los comportamientos que les estarían asociados. Tales brechas en los marcos referenciales bajo los cuales los distintos actores interpretarían los hechos y desarrollarían sus acciones, afectarían en el transcurso del proceso la coherencia de la visión estratégica original, así como la sintonía que se requeriría para la articulación convergente de las distintos roles, áreas y niveles de actividad de la organización y de las personas durante el proceso de cambio.

Similares efectos fragmentadores pueden visualizarse en los escenarios de construcción organizacional por medio de la agregación, proceso por medio del cual las organizaciones van incorporando unidades funcionales o sistemas técnicos, por medio de la yuxtaposición de estos en relación a los previamente existentes (Díaz Canepa, 2008a, op.cit.). Tal proceso, en el que se tiende a diluir el vínculo y filiación histórica, tanto entre las unidades funcionales, los miembros de la organización, así como entre las tecnologías utilizadas, iría derivando en la configuración de contextos 
organizacionales conformados por estancos sin más relación entre ellos que la pertenencia a un mismo referente genérico formal. Esto, con las consecuentes implicancias en el plano de las representaciones y prácticas colectivas, las que tienden a diversificarse e heterogeneizarse. De manera tal que, una construcción organizacional pensada quizás como un desarrollo continuo de elementos, culminaría en un agregado de componentes discontinuas.

Del mismo modo, la distinción entre continuidad y discontinuidad resulta dificultosa si se considera que los quiebres cualitativos que puedan acaecer en la conformación, contenido o naturaleza de la organización, podrían ser no sólo el producto de cambios abruptos y/o revolucionarios (cambios de tipo 2 según la nomenclatura propuesta por Watzlawick, Weakland, \& Fisch, 1974), si no que igualmente podrían ser el resultado, ya sea de la acumulación paulatina en el tiempo de determinados rasgos organizacionales e instrumentales, de redefiniciones relevantes en las relaciones que se dan entre elementos que conforman la organización o en las relaciones que se establecerían entre los miembros de la organización y/o entre ellos y el entorno, por ejemplo, en la frecuencia, volumen, secuencias, intensidad, pertinencia, causalidad, etc., de las interacciones en juego.

31 Desde esta perspectiva, si bien se puede estimar que el paso de una condición cualitativa a otra, constituiría un quiebre en la trayectoria organizacional al pasar de una lógica incremental de naturaleza continua, a una lógica de cambio radical, en discontinuidad con la condición pre-existente de la organización, la identificación en cuanto al momento de ocurrencia y de la cuantificación de los elementos que harían la distinción entre estos diferentes estados resultaría ser no obstante dificultosa. Así, por ejemplo, en el tránsito paulatino de una organización de producción a una organización orientada a la logística, o el paso de una organización básica a una organización profesional, o el cambio desde una impronta mecánica a una digital, por efectos de la incorporación creciente de soportes Tic's a través del tiempo, resulta prácticamente imposible determinar el hito que permita reconocer en qué momento y con base a que volumen de elementos nuevos, se ha producido el cambio en la naturaleza predominante de la actividad organizacional.

\subsection{Algunas Perspectivas Teóricas en Torno al Proceso de Cambio}

Buscando una categorización comprensiva de las distintas perspectivas que cruzan este campo disciplinario, Van de Ven et al. (1995, op.cit.) proponen cuatro grandes agrupaciones de las teorías que participan de este campo: teorías de ciclos de vida; teleológicas; dialécticas y evolutivas. Según estos autores las teorías centradas en una mirada sobre el ciclo de vida de las organizaciones poseerían paralelos con el desarrollo biológico, en el que cada etapa sucesiva de desarrollo evolucionaría desde la anterior y explican el desarrollo de la organización en términos de secuencias lógicas prescritas o naturales. Así, la forma organizacional que es homogénea en el estado embrionario se realizaría progresivamente, maduraría y se diferenciaría por medio de una secuencia unitaria (una sola secuencia de etapas o de fases), acumulativa (las características adquiridas en primeros tiempos se conservan en estado avanzado) conjuntiva (las etapas se relacionarían bajo un proceso subyacente común) y cada etapa del desarrollo sería precursora necesaria de las etapas sucesivas. Desde esta perspectiva, el contexto y 
los eventos externos pueden ser eventualmente la ocasión, pero no la razón o causa del cambio, ya que el proceso sería inherente a la naturaleza de las organizaciones.

Para las teorías de corte teleológico sería la meta organizacional la que motivaría el cambio y la trayectoria que recorrería, asumiendo que la entidad organizacional es de naturaleza propositiva y adaptativa. La organización construiría un estado previsto de llegada y tomaría medidas para alcanzarla, supervisando su progreso. Los autores de esta teoría ven el desarrollo como una secuencia repetitiva que va desde la formulación de una meta, la puesta en práctica de un plan, evaluación y modificación de las metas basándose en el aprendizaje y lo que la organización defina como propósito final. Diferentemente a la teoría basada en el ciclo vital, las teorías teleológicas no prescriben una secuencia de eventos prefigurados y plantea la propositividad del actor o de la unidad organizacional como motor para el cambio. Las teorías teleológicas no especifican que trayectoria seguirá una organización y sólo se podría hipotetizar un abanico de trayectorias posibles. Estas trayectorias debieran ser resueltas por las normas de la racionalidad o de la racionalidad de la acción (Brunsson, 1982), sin embargo también reconocen que el contexto y los recursos disponibles limitarían lo que se puede lograr, por lo que si bien los miembros de la organización no pueden eliminar las leyes naturales o las condiciones ambientales, pero pueden hacer uso de ellas para lograr sus propósitos (Commons, 1950; Gibson, 1988).

En cuanto a las teorías dialécticas, ellas plantearían que la organización existe en un mundo pluralista, en el que chocan acontecimientos, fuerzas y valores (Neal \& Northcraft, 1991). Estos competirían entre sí por la dominación y control organizacional, pero a la vez se encontrarían unidas complementariamente en torno a ejes contradictorios. Las oposiciones pueden ser tanto internas como externas a la organización en relación a metas, intereses de grupos, sistemas y paradigmas de gestión o bien entre organizaciones que compiten entre sí, etc. En este contexto, la estabilidad y el cambio organizacional se explicarían por las luchas y los acomodos entre las oposiciones en juego. El cambio ocurriría cuando los valores, fuerzas o acontecimientos en oposición ganarían suficiente energía para desequilibrar el status quo. Si los factores en oposición logran romper el status quo y sustituir a los anteriormente dominantes, estos últimos no desaparecerían, si no que permanecerían subsumidos en la organización, tensionando la estabilidad y continuidad de la nueva hegemonía, proyectándose ambos en la nueva síntesis que se produciría entre ellos.

Para la teoría evolutiva, el cambio sería producto de cambios acumulativos en las formas estructurales de poblaciones, organizaciones, comunidades, industrias o de la sociedad entera (Campbell, 1969; Hannan \& Freeman, 1977; Aldrich, 1979). El cambio operaría por medio de un ciclo continuo de variación, selección y retención. La creación de nuevas formas organizacionales se concibe como un fenómeno emergente y azaroso que ocurriría sólo (Campbell, 1969 (Ibid); Aldrich, 1979 (Ibid.)). La selección organizacional sucedería principalmente a través de la competencia por los recursos escasos, el ambiente seleccionaría y retendría las entidades y formas organizacionales que mejor se acoplen con la base de recursos del entorno. La mantención de estas entidades y formas organizacionales seleccionadas, ocurriría por medio del juego de fuerzas, inercias y de persistencia que ellas produzcan (Hannan et al., 1977, Ibid.), hasta que las condiciones de entorno varíen y exijan nuevas condiciones de acoplamiento. Pina et al. (2003, op.cit.) agregan a esta clasificación, el rol de la improvisación organizacional, en tanto que modo de marcar una nueva categoría de estilo de cambio 
organizacional. Dichos procesos ocurrirían indistintamente al interior de los modelos teleológicos, dialécticos y evolutivos de cambio, excluyendo a las formas de cambio guiadas por la lógica de ciclo de vida, las que por sus características seguirían una dirección predefinida. Estos autores plantean que las decisiones tomadas en las organizaciones responderían en muchos casos a la disponibilidad de recursos materiales, cognitivos, afectivos y sociales presentes en la organización, los que se ponen en juego en pos de acciones adaptativas, incrementales, dando lugar a cambios emergentes que no hacen relación con algún propósito de mayor alcance estratégico o temporal.

Más allá de las diferencias y cruces que presentan estas distintas perspectivas, lo que es ciertamente ineludible, es que los cambios suponen la definición de criterios referenciales que permitan reconocer lo distinto al interior de un contexto reconocible y de una secuencia temporal, con un antes y un después. En este sentido, por ejemplo, Golembiewski (1986) define tres tipos de cambio atendiendo al referencial considerado. Denomina estos tipos de cambio como Alfa, Beta y Gama, donde los cambios tipo Alfa refieren a aquellos donde se verifica una variación en el nivel de algún estado existencial de un objeto o situación en relación a un referente constante (ej: tasa de participación de mercado, siendo constante el tamaño del mercado, grado de automatización de los procesos, siendo constante el tamaño de la organización, etc.); cambios tipo Beta, dónde el cambio se produce en relación a la modificación de algún aspecto del referente (ej: baja de la tasa de participación de mercado, manteniendo el mismo volumen de venta, por efectos de una expansión del tamaño del mercado, nivel de competencia de las personas tras una modificación radical en los procesos y herramientas de producción); cambios tipo Gamma, serían aquellos en los que se reconoce una redefinición o reconceptualización de un ámbito significativo, un cambio mayor del marco de referencia (ej: cambio en la naturaleza del mercado, desde un sesgo técnico a un sesgo de servicios, cambio en los sistemas de contratos, desde un formato de trabajo por horario fijo a uno flexible).

Como se puede deducir provisoriamente, la calificación del tipo de cambio vivido por las organizaciones, sin duda supone un ejercicio analítico e interpretativo de cierta complejidad, y que ciertamente reviste una importancia práctica insoslayable tanto para la comprensión de los efectos sobre las personas y la actividad que estas desarrollan, como para la definición pertinente de las modalidades de gestión de los cambios a disponer.

Cabe destacar que una complejidad suplementaria para efectos de calificar la naturaleza de los cambios, reside en el hecho que los cambios organizacionales no implican necesariamente que todos los elementos que conforman la organización cesan de existir para ser sustituidos por nuevos elementos. Por el contrario, comúnmente el cambio al interior de una organización supone habitualmente la importante permanencia de elementos pre-existentes (personas, espacios, sistemas, procedimientos, tecnologías, etc.). Estos elementos pre-existentes, en muchos casos se redefinirían, rearticularían, reposicionarían o transformarían en algún plano y grado, según el nivel de impacto, extensión y grado difusivo de lo nuevo que se incorpore en la organización. Incluso es de considerar, que a pesar de la alta importancia de los cambios introducidos en la organización, algunos de los elementos pre-existentes, puedan permanecer inalterados, ya sea en razón de su peso e inercia estructural, a factores culturales, sociales y/o socioemocionales que se encuentren instalados en la 
organización. De modo tal, que no es improbable que sus características y dinámicas previas, puedan seguir incidiendo en algún grado la manera como la organización y las personas operen en el nuevo escenario generado por los cambios.

Dicho esto, si bien resulta evidente que los elementos que permanecen en la organización tras un cambio se ven afectados en mayor o menor medida, no es menos cierto que los nuevos elementos que se incorporen en la organización también se verían afectados y eventualmente transformados por efectos de integrarse a un territorio ya poblado en lo material, social y cultural. El escenario organizacional existente en el que se incorpore lo nuevo, ciertamente pondrá en tensión los atributos de lo nuevo, pudiendo generar formas impensadas de articulación y activación de sus propiedades. Esta dinámica de afectación mutua entre lo nuevo y lo que permanece de lo antiguo, iría definiendo una configuración emergente, con propiedades, estabilidades e inestabilidades propias, las que sin duda tendrían efectos impensados sobre la actividad de las personas, forzadas estas a definir contingentemente marcos referenciales y patrones de acción, gatillando eventualmente la exacerbación de procesos fundados en la exégesis de las reglas y la casuística en el accionar (Díaz Canepa, 2008a, op.cit.).

41 Tal dinámica, es sin duda un factor determinante para argumentar la necesidad de poner en juego modalidades diagnósticas, de monitoreo y de intervención que tomen como centro la situación y procesos efectivamente presentes en la organización. Ello implica hacerse cargo de la naturaleza a la vez multidimensional, histórica y situada que poseen los fenómenos organizacionales y en especial, de la actividad que las personas despliegan al interior de las organizaciones.

\subsection{Cambio y Resistencia al Cambio}

Las explicaciones en torno a lo que se denomina como resistencia al cambio, son sin duda variadas y responden a niveles lógicos diversos. K. Lewin (1952), quien marca significativamente esta línea de análisis, califica la resistencia, como fuerzas restrictivas que se mueven en dirección del mantenimiento del statu quo. Jermier, Knights \& Nord (1994), a su vez, complementan esta definición caracterizando la resistencia como un proceso reactivo, en el cual agentes inscritos en relaciones de poder se oponen a las iniciativas de otros agentes.

Estas definiciones han sido sin duda un gran aporte para entender los procesos de cambio desde una perspectiva social y dinámica. No obstante, no sería menos cierto que el uso del concepto de resistencia resulta a menudo problemático. Dent et al. (1999), por ejemplo, señalan que este concepto habría evolucionado desde considerarlo como una característica del sistema organizacional hacia una característica psicológica propia a los individuos que conforman la organización, y en especial de aquellos que ocupan roles subalternos, generándose una distorsión de su sentido original. Así, por ejemplo, como lo indica Watson (1982), se habría vuelto un hecho común que los directivos de las organizaciones tiendan a percibir negativamente la resistencia y visualicen a aquellos que resisten como desobedientes, eludiendo hacerse cargo de los fundamentos de los reparos a los cambios propuestos. Así, según lo apunta Krantz (1999), con el tiempo este concepto se habría ido transformando en un modo, ni siquiera tan oculto, para culpar a aquellos que tienen menos poder, de los resultados insatisfactorios de los esfuerzos de cambio. Dentro de esta lógica, tal como ya se indica más arriba, la propia estructura y dinámica de ciertos modos de realizar procesos de cambio, como por 
ejemplo los desplegados en cascada (Hannan et al., 2003), pueden generar espacios para el desarrollo de comportamientos fácticamente divergentes con respecto a los proyectos de cambio. Esto, sin que los propios actores tengan necesariamente conciencia de estas contradicciones, ni comprendan porque se les señala como resistentes al cambio.

Un ingrediente ideológico suplementario, y que forma parte del discurso de la época actual, ha sido el considerar que el cambio sería siempre una solución en sí misma (Soparnot, 2011), asumiendo que el cambio es siempre beneficioso (Thévenet, 1988). Sin embargo, no cabe duda que el cambio, al poner en movimiento elementos que configuran el sistema organizacional, no sólo genera posibilidades de optimización y desarrollo de la organización, si no que igualmente debilita las bases sobre las que se sustentaba el equilibrio organizacional previo, pudiendo eventualmente abrir la puerta a la inexperiencia (Hannan \& Freeman, 1989) y a la improvisación sin rumbo (Pina \& Vieira, 2003), alternativas que pueden ser arriesgadas y costosas si no se logra restablecer un nuevo nivel de equilibrio que, a lo menos, compense el esfuerzo y recursos exigidos por el cambio. Tales situaciones conducen a menudo que tanto actores internos como externos tiendan a favorecer la estabilidad y predictibilidad del comportamiento organizacional y se muestren al menos escépticos frente a las bondades ofrecidas por los proyectos de cambio, o como lo señala Piderit (2000), que las personas tiendan a presentar una actitud ambivalente frente a los cambios: por una parte, reconociendo la necesidad de realizarlos, pero por otra, manifestando dudas sobre algunos de sus aspectos o modos de realizarlos, de manera tal que la actividad de las personas puede eventualmente adquirir formas erráticas o ritualizadas.

Siguiendo la línea planteada por Pina et al. (2003, op. cit.), hay que considerar que los procesos de cambio poseerían de por sí un carácter cambiante. Esto, por efectos de las propias condiciones emergentes que cruzan estos procesos y las condiciones que permitan la factibilidad de ciertas decisiones y cursos de acción de manera tal que, a menudo, más que por una estricta consistencia en torno a propósitos predeterminados, muchos cambios ocurrirían de manera más bien casual en razón de las respuesta ad-hoc que los miembros de la organización darían a situaciones cotidianas puntuales. Así de pronto, los procesos de cambios tomarían a veces derroteros no previstos, generando escenarios en los que los miembros de la organización no puedan necesariamente visualizar de modo nítido la secuencia descrita por Lewin de tres fases sucesivas: descongelamiento, movimiento y recongelamiento (Lewin, 1947b). Los miembros de las organizaciones tenderían en consecuencia a sentir que nunca se alcanzaría la fase de recongelamiento, introduciéndose de este modo cuotas de incertidumbre sobre los hitos a transitar y momento de culminación de los procesos de cambio en curso (Mack, Nelson \& Campbell-Quick, et al.,1998). Ello derivaría en una dilución de los criterios de pertinencia que debieran gobernar la articulación de la actividad individual y colectiva en pos del logro de los objetivos organizacionales, de manera tal que tanto la distinción entre lo urgente y lo importante, así como las coordinaciones internas tiendan a verse degradadas en beneficio del accionar reactivo y disperso de los agentes organizacionales.

Cabe en este sentido destacar que todo proceso de cambio implica el debilitamiento de las reglas y condiciones que sustentaban la situación organizacional y funcional previa. Del mismo modo, es habitual que al momento de iniciarse el cambio, las nuevas reglas y condiciones organizacionales no se encuentran aun plenamente instaladas y vigentes. 
Por ello, es que por lo general, los procesos de cambio conllevan períodos en que los sistemas de trabajo tiendan a degradarse antes de retomar una trayectoria positiva, en el mejor de los casos (figura 2).

Figura 2: Curva de aprendizaje y desempeño organizacional durante el cambio según Davis \& Newstrom (1991)

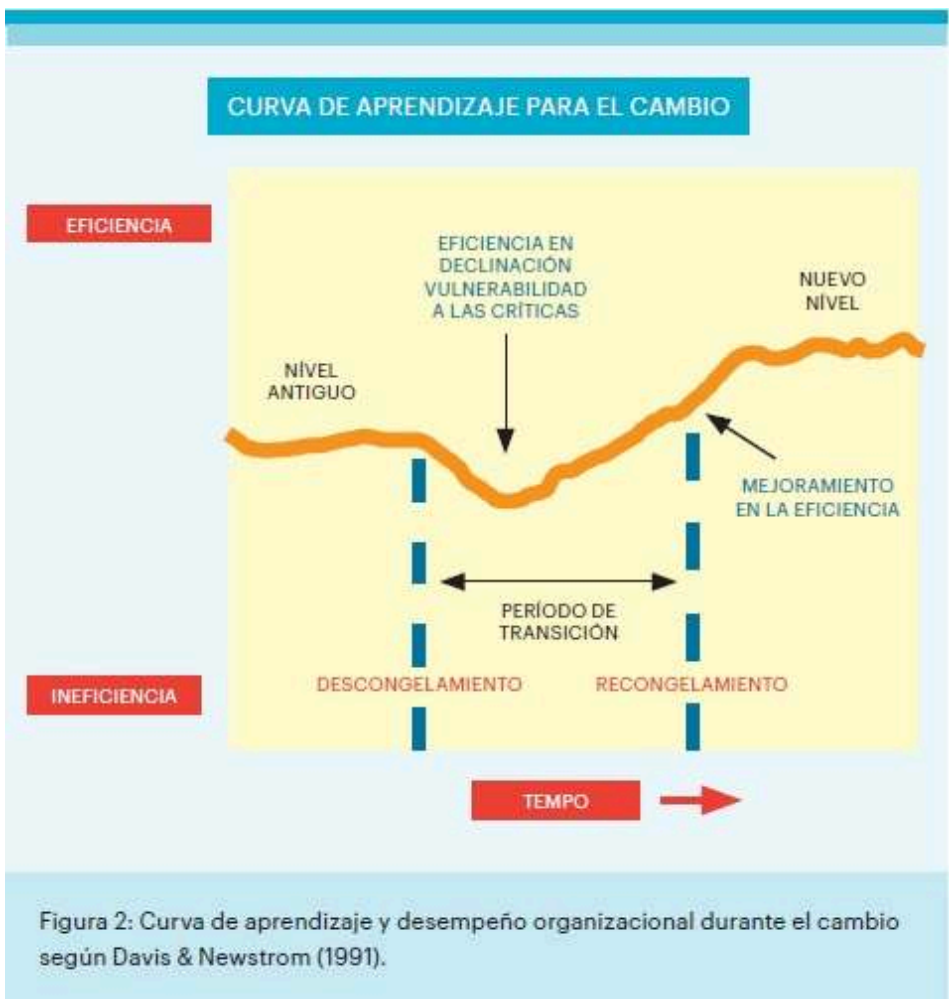

Tal degradación sin duda es un ingrediente que contribuye a exacerbar la incertidumbre, la conflictividad y el estrés organizacional. Desde esta perspectiva, cabe recordar que incertidumbre y estrés en el trabajo son fenómenos que se encuentran comúnmente asociados $\mathrm{y}$, tal como se muestra en el estudio realizado por Vakola \& Nikolau (2005), existiría igualmente una significativa relación entre estrés ocupacional y actitudes frente al cambio, dinámica que derivaría entre otros fenómenos, en un incremento de licencias médicas, de la intención de dejar la organización y de la rotación efectiva (Fugate, et al., 2008).

En este sentido Dos Santos Paulino (2009), señala que el propósito adaptativo que subyacería a los esfuerzos de cambio, podrían derivar en una merma de las fortalezas inercicas que poseería la organización. Así, no es improbable que la aparición de fenómenos que puedan ser atribuibles a lo que se denomina como resistencia al cambio, respondan a dinámicas que tienen su origen en la propia forma en la que se desarrolla y gestiona el proceso de cambio, más que en las actitudes a priori que las personas puedan tener sobre los propósitos de los cambios. Una de esas formas que importa señalar, es cierta tendencia que se ha hecho habitual en algunas organizaciones, y que se expresa en una compulsión al "cambio por el cambio". Así, por ejemplo, es posible observar a menudo el recurso a frecuentes cambios de estructura y personas, sin que ello involucre cambiar las lógicas que subyacen a las prácticas organizacionales, y sin que estos cambios hagan necesariamente relación directa con las causas que se encuentran a la base de las problemáticas que afectan los desempeños de la 
organización. Esta tendencia se explicaría en buena medida por el hecho que, emprender cambios de naturaleza más sustantiva, resultan difíciles de asumir por los directivos, dados los riesgos y dificultades que ellos implican (Kanter, 1988), siendo los cambios de estructura y personas más fáciles y controlables a realizar, dejando la sensación que "algo se ha hecho" para enfrentar las problemáticas en cuestión.

Tales dinámicas redundan frecuentemente en lo que se denomina como "cambios excesivos" (Stensaker et al., 2002, op. cit.), procesos en el que los directivos recurren a sucesivos cambios en diferentes áreas, sin relación evidente entre ellos y apuntando a situaciones de diverso orden, conllevando frecuentemente efectos sobre los niveles de certeza y de estrés organizacional, con los consecuentes impactos en la forma en que las personas organizan y desarrollan su actividad. Así, como lo indica Hatchuel (1996), en estas situaciones se tendería a producir una distorsión progresiva de la prescripción determinada en el diseño original del trabajo, y tal como ya se ha señalado, abriendo espacios a la exégesis y formas casuísticas de la actividad ante las contingencias que las personas deben enfrentar durante su actividad cotidiana (Díaz Canepa, 2008a, op.cit.).

Así, a pesar que los cambios puedan brindar oportunidades para la renovación, sería habitual que tienda a instalarse en las organizaciones el predominio de la tendencia a "mantener el statu quo", tanto durante como después de los cambios, ya que las personas tenderían a experimentar o percibir preferentemente las consecuencias negativas y a no visualizar crecimientos en su situación de trabajo o de la efectividad organizacional (Lazarus, 1991). De este modo, si se sigue lo que señalan autores tales como Dent et al. (1999), las personas por lo general no se resistirían al cambio en sí, si no que resistirían a las eventuales pérdidas de status, de remuneraciones o de confort. Para estos efectos, sería igualmente relevante el balance percibido por las personas entre los recursos que la organización disponga y las demandas asociadas al proceso de cambio (Van Emmerik, Bakker \& Euwema, 2009), pues de ello dependería en gran medida la posibilidad que las personas tendrían para rearticular su actividad en función de las nuevas exigencias.

\subsection{Cultura Organizacional y Cambio}

Un marco referencial fuerte que puede facilitar o inhibir las disposiciones al cambio, es sin duda la cultura organizacional (Detert, Shroeder \& Mauriel, 2000), pues esta operaría como un contexto (Geertz, 1973) que validaría o invalidaría las disposiciones y comportamientos de los miembros de la organización. No obstante el carácter dinámico de los contextos, producto de la historia, la interacción con otros contextos y la dinámica contingente de los actores organizacionales, estos tenderían a gozar de cierta estabilidad que los haría reconocibles en tanto que configuraciones significativas, que permiten e incentivan la interpretación y particulares modos de despliegue de la actividad por parte de los actores organizacionales. Esto ocurriría particularmente por efectos de dos mecanismos principales: 1 . La rutinización estructurante de los roles e interacciones sociales en el tiempo y en el espacio; 2. La proyección de sus significados, a través de su cristalización en la cultura organizacional (Martin, 2002).

Según Trompenaars (1993), una cultura homogénea podría tender a ser recalcitrante a los cambios, ya que los miembros de un grupo con una cultura común tenderán a una definición compartida de las situaciones que viven, definiendo patrones de entendimiento y sistemas de significados en relación al status, la jerarquía y las 
relaciones entre las personas (Danisman, 2010) y marcando la manera a través de la cual un grupo de personas soluciona habitualmente los problemas (Schein, 1992, 1996) y despliega su actividad, generando un marco de certidumbre que facilitaría la cotidianeidad.

No obstante la existencia de un marco referencial común, que reúna a los miembros de una organización, es igualmente posible reconocer que los contenidos culturales que poseen las organizaciones raramente son completamente homogéneos, presentando a menudo diversos significados prácticos bajo el paraguas de conceptos genéricos comúnmente aceptados (ej: equidad, lealtad, compromiso, calidad, etc.). Más aun, estos conceptos tenderían a ser reinterpretados en función de los requerimientos adaptativos que las personas y las organizaciones deban enfrentar a través del tiempo (Bateau, 2000), proceso que comúnmente se ubicaría a la base de parte significativa de los cambios que viven las culturas: ellas evolucionarían en gran medida desde sus propias referencias, relacionando los nuevos significados con los previos o extendiendo los significados previos a nuevos contenidos, generando así un hilo conductor que permita sostener la continuidad identitaria de la organización, así como la congruencia del quehacer de sus miembros.

Dicho esto, cuando varía el contexto interno o externo, este cambio confrontado a la cultura organizacional puede operar como efecto principal sobre el comportamiento de las personas, ya sea gatillando o moderando las dinámicas internas, posibilitando la reinterpretación y proyección de significados, facilitando u obstaculizando la orientación y desarrollo de los procesos de cambio, dando soporte o distorsionando la actividad que las personas despliegan en función del logro de objetivos.

\subsection{Otros Factores que Inciden en los Cambios}

En un sentido propositivo, Holt, Helfrich, Hall, \& Weiner, (2010), sostienen que la aceptación a los cambios dependería de cuatro factores, los que definirían el nivel de preparación al cambio de las personas y las organizaciones. Estos factores serían: a) Individuales Psicológicos (IP), que reflejarían el grado en que las personas reconocerían que un problema debe ser abordado y se encuentren de acuerdo con los cambios requeridos por las personas y la organización. b) Individuales Estructurales (IS), relacionados con el conocimiento, las habilidades y la capacidad de las personas para desempeñarse una vez que se implemente el cambio; c) Organizacionales Psicológicos (OP), referidos a creencias relevantes, compromiso colectivo y la eficacia colectiva de los miembros de la organización y d). Organizacionales Estructurales (OS), relativas a los recursos humanos y materiales, canales de comunicación y la política formal.

Todos estos factores, siendo sin duda relevantes para efectos de ponderar las eventuales brechas organizacionales para enfrentar los cambios, no dan sin embargo luces suficientes para definir cómo implementar las estrategias apropiadas para acompañar dichos cambios. Así por ejemplo, a pesar de contar con circunstanciados diagnósticos en materia de conocimientos y competencias necesarias para el desempeño en el estado futuro de la organización, lo habitual es encontrar estrategias de capacitación basadas en modelos de aprendizaje infantil, enfatizando los formatos orientados a promover la acomodación cognitiva ante las nuevas disposiciones orgánicas o instrumentales, sin considerar las particularidades del aprendizaje adulto, el que se sustenta en una lógica fundada en los propósitos de la actividad y las 
competencias que las personas ya poseen, permitiendo así mitigar los efectos desarticuladores que pueden derivarse de los cambios y sostener el hilo conductor del quehacer, expandiendo la identidad de rol y las competencias, dando contexto y sentido a la incorporación de lo nuevo (Engeström, 1999 (op.cit.); Díaz Canepa, 2005 (op.cit.) y 2008b).

57 A su vez, considerando el plano comunicacional, Bryant \& Frahm (2011), por ejemplo, señalan la necesidad de desplegar estrategias comunicacionales inclusivas, cambiando la lógica tradicional basada únicamente en argumentos desarrollados por el ápice de la organización. Apuntan que, mediante el reconocimiento e incorporación de las múltiples narrativas presentes en la organización en la comunicación del cambio, sería posible aumentar la probabilidad que los miembros de la organización participen activamente de la comunicación y del propio proceso de cambio, disminuyendo las eventuales resistencias. Desde esta perspectiva, un factor relevante a considerar es la mayor o menor presencia de narrativas influyentes al interior de las organizaciones. Así, por ejemplo, la presencia de organizaciones sindicales y agrupaciones de distinta naturaleza que posean historia y arraigo al interior de la organización, requerirán muy probablemente de abordajes e interlocuciones distintas a las que puedan darse en organizaciones en las que las narrativas se encuentren principalmente mediadas por las relaciones interpersonales (Roscigno \& Hodson, 2004), así como por normas y referencias identificatorias grupales (Jimmieson, Peach \& White, 2008).

\section{Un Enfoque para la Intervención en Gestión del Cambio}

En este punto abordaremos algunos tópicos que nos parecen relevantes a considerar en el desarrollo de los procesos de cambio, por sus efectos sobre la actividad y la situación de las personas.

\subsection{Reconocer la Complejidad Derivada de la Temporalidad de los Eventos}

59 El enfoque de intervención en gestión del cambio que se propone aquí, se sustenta en las derivaciones que resultan del análisis de casos de distinta naturaleza de cambio organizacional, los que no serán expuestos en detalle, si no que serán referidos puntualmente de manera a ejemplificar algunos aspectos de la perspectiva que se busca ilustrar aquí.

Dicho muy esquemáticamente, el caso de cambio en Metro de Santiago, responde fundamentalmente a los efectos de las sucesivas expansiones de la red, iniciada en 1975 con 2 líneas, las que fueron extendiéndose paulatinamente en el transcurso del tiempo. Con posterioridad, a partir de 1995 se incorporó una nueva línea, y luego entre 2005 y 2006 se agregaron sucesivamente 2 nuevas líneas. Tales cambios conllevaron fuertes reconfiguraciones en la complejidad de la red, con cambios del volumen, asignación y modalidad de contrato de los conductores, así como modificaciones importantes en la estructura y tiempos efectivos de conducción, alterando las condiciones de ingreso y salida a los turnos, así como el control que los conductores tenían sobre los momentos y 
tiempos de pausa y colación. Del mismo modo, ha traído importantes efectos en la forma de realización del mantenimiento de trenes y vías.

61 En el caso de la ENAP (Díaz Canepa, Poblete \& Torres, 2005), el modo de cambio histórico ha sido bajo dos ejes principales: 1. La agregación en el tiempo de nuevas unidades de negocio, separadas geográficamente y con distinto giro funcional y 2 . El giro desde una lógica extractiva a una de refinación y posteriormente a una basada en procesos logísticos. Dichos cambios han repercutido tanto en la diversificación de la cultura interna, así como en la forma en que las personas articulan su actividad interna. En cuanto a Telefónica Chile, es posible relevar cambios derivados tanto de importantes modificaciones en su estructura de propiedad, en sucesivos cambios en su estructura organizativa, así como en el desarrollo de diversos tipo de negocios (telefonía fija, celular, cable e internet), atravesando por variados episodios de fusión con empresas del ámbito de las telecomunicaciones (Díaz Canepa, Cox, Bilbao \& Valdivia, 2001; Díaz Canepa, Berkovich, \& Preiss, 2006). Tales dinámicas calificarían en el cuadro descrito por Stensaker, et al. (2002 op.cit.), denominado como “cambio excesivo".

Por último, el proceso de conformación del Hospital Público de la Florida, ha seguido una lógica de cambio planeado, partiendo desde el diseño del proyecto, pasando por un proceso de confluencia hacia su conformación de dos centros de salud existentes y de profesionales reclutados desde el mercado de la salud, culminando en la incorporación de sistemas, modelos y procesos de atención innovadores para la realidad chilena (Díaz Canepa, Arancibia \& Drobny, 2015).

En un intento de recoger aspectos sustantivos que se pueden derivar de estas experiencias, el modelo que se propone aquí se define por considerar el carácter multidimensional, multinivel y sincrónico de los factores que inciden sobre la trayectoria de los cambios organizacionales (Whelan-Berry, Gordon \& Hinings, 2003).

Tal como ya se ha señalado, todo proceso de cambio involucra cuotas importantes de eventos y fenómenos emergentes y presentan desarrollos de variado contenido que se ubican en niveles diversos $\mathrm{y}$, en este sentido, los procesos de cambio planeado no escapan a estas condiciones. Realizar un cambio planeado no implica necesariamente que su desarrollo se articule como una sucesión de etapas discretas, en el que una nueva etapa comienza al momento en que termina la etapa previa. Por lo general, los procesos de cambio planeado, también se caracterizan por la coexistencia temporal de etapas de distinta naturaleza, incidencia y en distintos estados de desarrollo (ver figura 3). Esta dinámica define en gran medida el carácter complejo de los procesos de cambio. 
Figura 3: Superposición temporal de las fases del procesos de cambio. En la figura, tanto la abscisa como la ordenada son de carácter referencial, pudiendo ser cuantificadas con distintos parámetros en función del proceso en cuestión (elaboración propia).

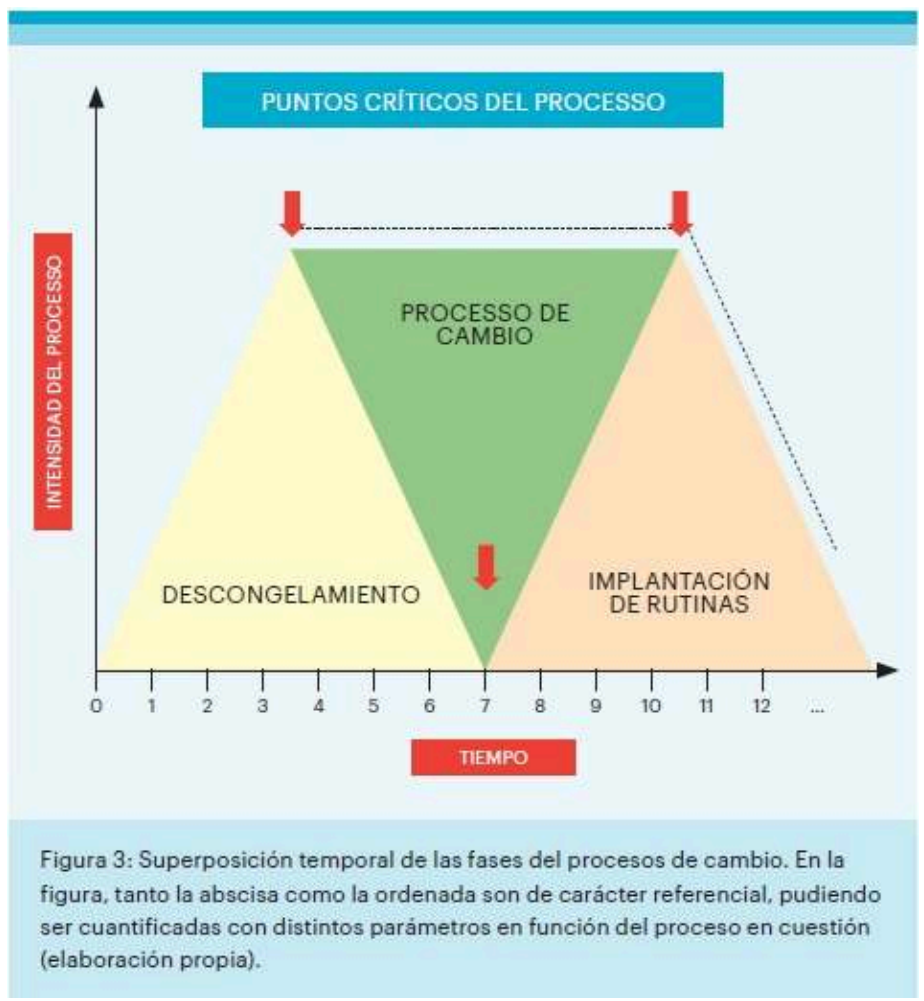

Ello quiere decir que las distintas etapas y la temporalidad de los eventos que ocurran en cualquiera de las dimensiones organizacionales van a seguramente coexistir con varias etapas y eventos que responden a otras dimensiones y niveles organizacionales (figura 4). Esta coexistencia va a eventualmente producir contextos y condiciones de realización que afectarán a su vez y en alguna medida el desarrollo de cada una de las dimensiones en juego. Tal superposición define un significativo desafío para la organización y direccionamiento de la actividad que las personas realicen, pues supone la capacidad de distinguir entre diversos contextos de acción que coexisten en el tiempo y que requieren tipos de respuesta focalizadas y competencias distintivas para su tratamiento. 
Figura 4: Superposición temporal de las dimensiones del procesos de cambio en las distintas fases (elaboración propia)

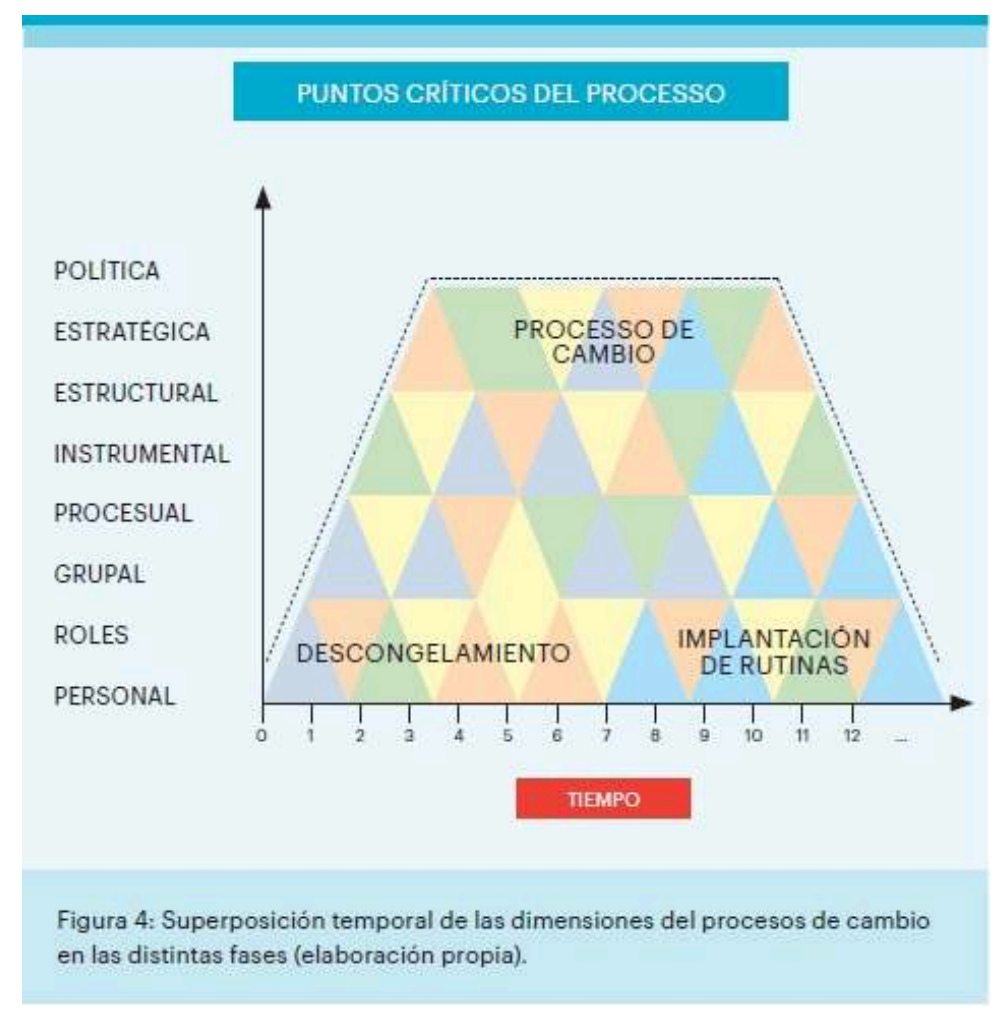

67 No obstante el carácter multidimensional, multinivel y sincrónico de los factores que concurren al proceso de cambio (Whelan-Berry, et al., op.cit., 2003), la pertinencia y criticidad de estos factores tienden a tomar grados de relevancia distinta, según los momentos de los procesos de cambio y de los contextos en que estos proceso de cambio se desarrollen. Tal como lo plantean Erickson \& Schultz (1997, op.cit.), no resulta obvio saber cuando es un contexto. Así, por ejemplo, si en la etapa de descongelamiento, lo central de la actividad se encuentra definido por la necesidad de remover aspectos que dificultan la instalación de nuevas formas de acción, en la etapa de desarrollo del proceso de cambio, el énfasis se ubica en la generación de alternativas de acción, mientras que en la etapa de implantación de rutinas, el acento está en la sistematización de los nuevos modos de operar. Si estos contextos tienden a coexistir durante ciertos períodos del proceso de cambio, es probable que ello derive en situaciones y dinámicas contradictorias en cuanto a la definición de prioridades, orientación, orden y formas de la actividad que los distintos actores organizacionales deben desplegar.

Una de las dificultades mayores de los procesos de cambio deriva del hecho que la sincronía de factores presentes en cada fase del proceso, no implica necesariamente que el estado de desarrollo requerido y convergencia de ellos se encuentren asegurados. Por el contrario, es frecuente en los procesos de cambio enfrentar la necesidad de lidiar con los descalces temporales y de secuencias en el desarrollo tanto de los factores que lo configuran, como de aquellos que puedan incidir sobre este. En efecto, el desarrollo armónico de los cambios no sólo requiere que se conjuguen distintos factores y niveles de acción en las distintas fases del proceso, sino que también es determinante el orden en el cual se suceden las acciones, eventos y contextos. En este campo, el orden de los factores, si afecta los resultados. 
69 A modo de ejemplo referencial de cómo la ausencia de sincronía y la alteración del orden de ocurrencia de los eventos durante el proceso de cambio afecta los resultados, es posible señalar que durante el proceso de instalación y consolidación del Hospital Público de la Florida (Díaz Canepa et al., 2015.), surgió una multiplicidad de dificultades en la operacionalización de sus procesos clínicos y administrativos por efectos de los desfases producidos entre las distintas dinámicas en juego durante el proceso de instalación y puesta en marcha del hospital. Un primer factor incidente, radicó en la presión política por lograr una pronta apertura del hospital, proceso que obligó a una puesta en marcha en etapas de los distintos servicios clínicos, dificultando la articulación sistémica de los distintos procesos de derivación interna. Esta situación se vio a su vez exacerbada por los importantes rezagos por parte de la empresa proveedora en la puesta en marcha del sistema informático que los sustentaba, situación que tuvo un significativo impacto en la forma bajo la cual se desplegó la actividad concreta de los distintos servicios y categorías de personal de la institución para dar cuenta, tanto de las exigencias asociadas a la atención de pacientes, como de la propia gestión administrativa interna. La instalación de procedimientos "degradados" desarrollados durante el período inicial, generaron inercias complejas que fueron impactando el ulterior desarrollo del proyecto, y en particular la forma de articular y soportar las distintas actividades del hospital. Tal situación, obligó no sólo a poner un marcado acento en los aspectos técnicos y funcionales del sistema informático, distrayendo recursos y energías que debían abocarse preferentemente a consolidar los procesos de atención clínica, sino que además implicó desarrollar un importante esfuerzo de socialización, necesario para generar las condiciones de reelaboración de las representaciones compartidas que permitiesen sustentar adecuadamente la actividad colectiva del personal.

70 Así, en este caso, factores contextuales externos, asociados a factores procesuales y técnicos, fueron impactando las formas en las que se actualizaron las actividades desplegadas por las personas, generando un bucle negativo en el proceso de consolidación del proyecto, obligando a desarrollar importantes acciones de mitigación.

71 De este modo, tal como lo señalan los autores de la Teoría de la Contingencia (Demers, 2007, op.cit.), y como en parte se verifica en el caso arriba expuesto, la trayectoria y eventos que acaecen en los procesos de cambio organizacional se ven influenciados por factores contextuales ajenos a la organización que fuerzan a arreglos adaptativos. Ello implica no sólo la necesidad de reconocer los contextos externos que pueden afectar el desarrollo del proceso de cambio, si no que igualmente se hace necesario contar con estrategias de tratamiento adecuadas para positivar o mitigar los eventuales eventos y efectos negativos que deriven de las dinámicas del entorno organizacional.

De igual manera, en el caso de ENAP, es posible señalar que si bien su desarrollo organizacional se realizó fundamentalmente bajo mecanismos de agregación de nuevas unidades de negocio (ver figura 5), respondiendo a una lógica voluntarista, en contraste, los giros en los énfasis de su actividad productiva han sido más bien el resultado de respuestas adaptativas a las condiciones del entorno económico (mercado del petróleo), así como a las capacidades materiales y técnicas disponibles para sostener su actividad (baja disponibilidad de combustibles fósiles en el país, alta disponibilidad de competencias en gestión de procesos técnicos) (Díaz Canepa et al., 2005, op.cit.). 
Figura 5: Línea de tiempo del desarrollo organizacional por agregación en ENAP

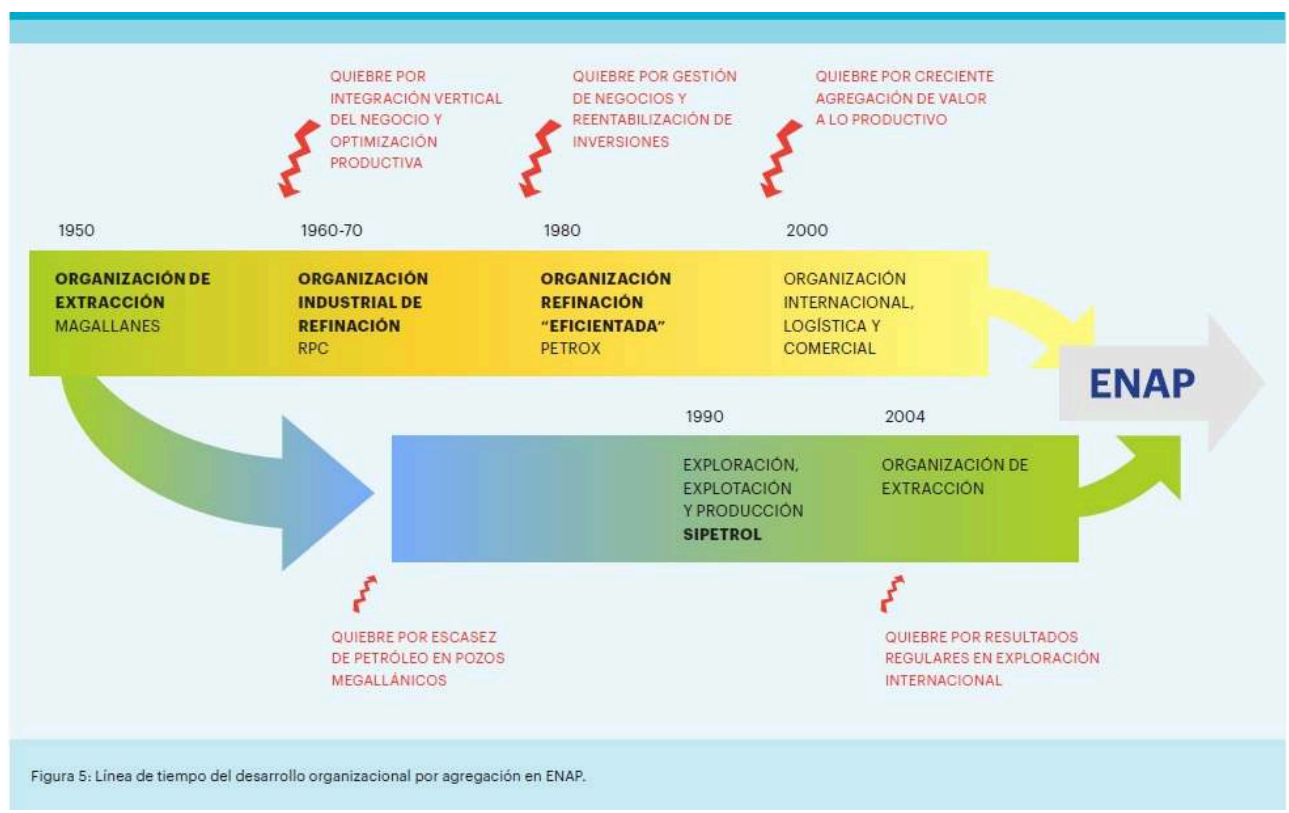

\subsection{La Negociación del Sentido de la Actividad}

En escenarios en los que se incrementa la incertidumbre, como ocurre habitualmente en los procesos de cambio, es clave tener en cuenta que el conocimiento, los roles, intereses y capacidades de influencia de los actores organizacionales y de aquellos que puedan influir sobre la organización, se encuentran desigualmente distribuidos. Hacerse cargo de esta realidad de manera de incentivar comportamientos compatibles con el proceso de cambio, implica la identificación del mapa político de la organización y de los actores externos que pueden influir sobre ella. Esto con el objetivo de sustentar la definición de modalidades de participación pertinente, que aseguren que los distintos actores se integren y contribuyan desde sus propios ámbitos de acción al proceso, dándoles influencia sobre aquellos aspectos que los afectaran directamente, incrementando así su compromiso con las acciones a desplegar durante el proceso de cambio, en niveles y ámbitos que hagan relación directa con su rol, su actividad, o con su vínculo respecto a la organización, si se trata de agentes externos. En este sentido, es igualmente necesario apoyar y desarrollar habilidades de enfrentamiento de situaciones emergentes de los agentes y responsables críticos del proceso de cambio. Ellos pasan a ser referentes insoslayables para la interpretación de las reglas y orientación de la actividad de las personas llamadas a implementar los cambios.

De igual manera, el desarrollo de las estrategias de capacitación o de inducción a las nuevas formas de trabajo, debieran articularse desde una lógica comprensiva basada en los propósitos y contextos de acción que subyacen a la actividad de las personas. Vale decir, que más allá de los aspectos formales o instrumentales que puedan estar presentes en el nuevo escenario, importa incorporar el carácter procesual y situado de las actividades a desplegar, pues de ello depende en buena medida la adecuada apropiación de lo nuevo por parte de las personas. Complemento de ello, el desarrollo de estrategias de supervisión orientadas al desarrollo y refuerzo de la autonomía de las personas en el ejercicio de sus roles y actividad, es igualmente necesario para efectos de 
sostener las dinámicas de aprendizaje expansivo y de apropiación de lo nuevo (Engeström, 1987). En definitiva, la óptica que preside esta propuesta, es la de generar grados relevantes de apropiación de los cambios por parte de las personas, rompiendo con la habitual lógica centrada en procesos de control y reproducción normativa de indicaciones prescriptivas.

Es necesario recordar que las organizaciones, los sistemas de trabajo, al igual que las tecnologías, son antes que nada ideas transformadas en roles, reglas, acciones, coordinaciones y artefactos (Rabardel, 1995 (op. cit.); Engeström, 1999 (op. cit.); Nathanael, et al., 2008 (op.cit.). Por ello, es que para efectos de generar cambios, es posible contar con importantes márgenes de libertad para definir los propósitos y formas de operar de estos distintos factores. Dicho esto, hay que señalar que el proceso de cambio no se resuelve meramente en el desarrollo de una lógica objetiva y racional, si no que resulta crítico integrar las subjetividades presentes en la organización. Importa, en este sentido, considerar la definición de políticas, estrategias y contenidos de comunicación focalizada (Nelissen \& Van Selm, 2008), de manera que la comunicación y los medios a desplegar, se orienten en función de los intereses, características y condiciones de acceso a los medios de los respectivos actores. Es de recordar que la comunicación es antes que nada un proceso y un fenómeno de influencia, cuestión que define el sentido del desarrollo de una estrategia comunicacional, pero igualmente define los requerimientos de instancias de escucha y negociación con los agentes organizacionales. Vale decir, interesa definir cuáles son los comportamientos sobre los que se espera incidir y a su vez, reconocer e integrar igualmente las expectativas y necesidades que subyacen a las narrativas de los distintos interlocutores organizacionales.

Esta focalización en actores diversos, no supone la generación de contenidos contradictorios, por el contrario, es clave que el diseño comunicacional resguarde la congruencia general de los contenidos y que sus distinciones y matices refieran a énfasis en los intereses, situaciones y estilos particulares de los actores (Duck, 2005). Para estos efectos, la gestión de la comunicación requiere alinearse con la lógica de conducción del proceso de cambio, por lo cual es recomendable que esta función se centralice y articule desde el ápice de la orgánica que conduce y gestiona los cambios, de manera que la incorporación de los distintos actores se realice en un marco de diálogo coherente y convergente.

\subsection{Factores Moduladores y Prescriptivos}

De un modo general y metafóricamente hablando, la gestión del cambio puede ser asimilada al enfrentamiento de una situación de crisis, dada la creciente degradación de los referentes conocidos y la probable debilidad prescriptiva de los nuevos referenciales que el proceso de cambio implica. En consideración a ello es que resulta indispensable el desarrollo de una capacidad de conducción que permita asegurar la mantención del hilo conductor del proceso por medio del despliegue de un estilo transformacional de liderazgo (Boga et al., 2009) y la constitución de una orgánica que conduzca el proceso de cambio (Hoogendoorn, Jonker, Schut, \& Treur, 2007). Esta orgánica debiera contar con amplio soporte del ápice organizacional, un amplio acceso a las áreas afectadas por los cambios proyectados, las competencias necesarias para 
identificar las situaciones relevantes a considerar y las capacidades para canalizar los recursos organizacionales en función de los requerimientos del proceso.

Un riesgo importante a considerar durante el proceso de cambio es la probable exacerbación de dinámicas fragmentarias y parcelarias al interior de la organización. En efecto, la modificación de las formas habituales de hacer las cosas por efectos de los cambios incorporados en la organización, puede afectar no sólo los contornos y orientación de los roles y de la actividad específica que las personas ejercen, si no que igualmente puede alterar la articulación entre roles y áreas de la organización. Resguardar niveles de integración básicos del quehacer colectivo, es sin duda una de las tareas de mayor exigencia para la gestión del proceso de cambio. Ello implica generar estrategias y acciones que faciliten la convergencia y congruencia entre los distintos niveles organizacionales: personas, grupos y sistema total (Burke, 2008, op.cit.), así como de estos con los soportes operacionales de la actividad que realizan.

Así, por ejemplo, los procesos vividos por el Metro de Santiago, en los que su dotación se ha visto crecientemente fragmentada por efectos de la extensión de su red, con la consiguiente redestinación funcional de importantes segmentos de conductores. Estos cambios han implicado importantes efectos en la forma en que la actividad y sus costos se han ido produciendo en el tiempo. A título referencial, a continuación se presentan los antecedentes de trastornos óseos y musculares (TOM, gráficos 1 y 2) y de accidentes del trabajo (AT, gráficos 3 y 4) de conductores en función del tipo de turno en que se encontraban asignados (mañana o tarde) y el tipo de educación terminal alcanzada (educación media, técnica superior, universitaria) entre los años 1987 y 2002.

Gráficos 1 y 2: Licencias médicas por TOM presentadas por conductores de metro entre 1987 y 2002

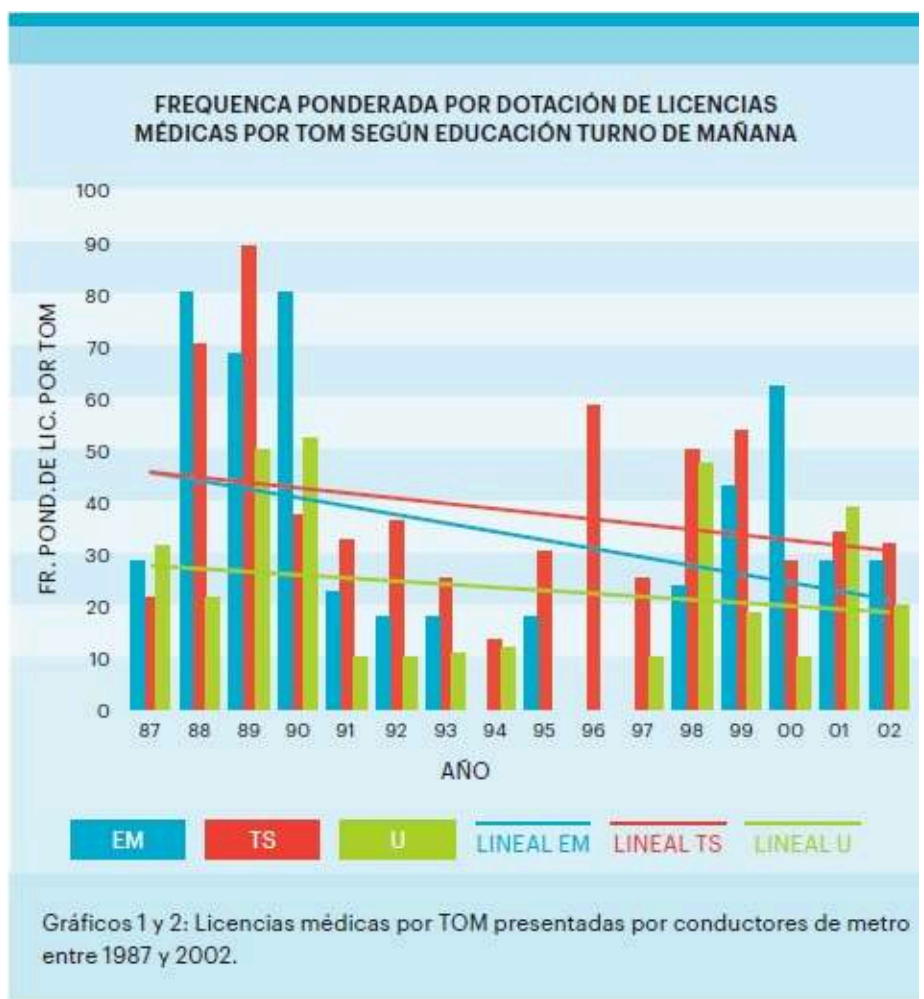




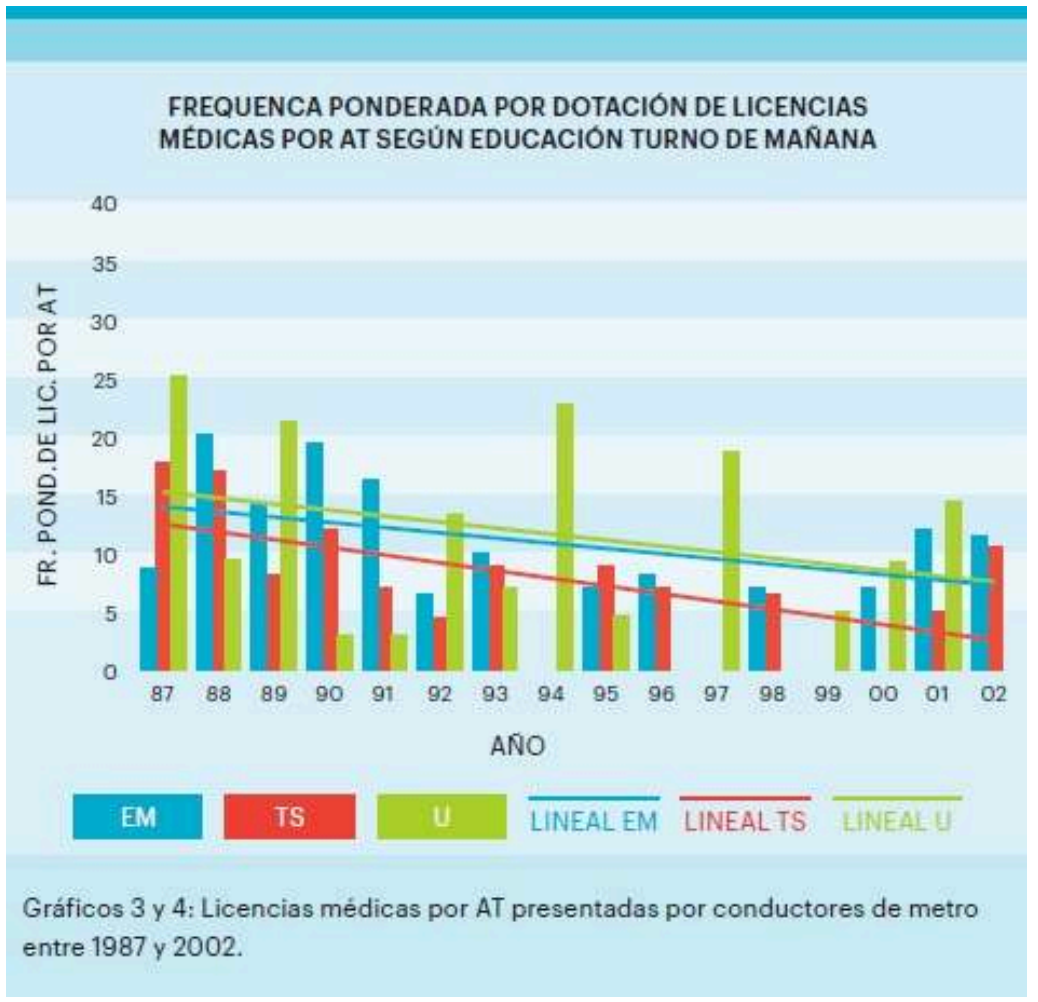

81 Como es posible ver, a través del tiempo y asociado a los cambios ya mencionados, los indicadores de TOM y AT siguen una evolución aparejada a los distintos escenarios operacionales generados en la red a través del tiempo. Así es posible reconocer 3 diferentes épocas. La primera, entre el año 1987 y 1990, la operación de trenes estaba marcada por dinámicas de regulación espontánea que se traducían en dinámicas incrementales de carga de trabajo (Díaz Canepa 2008b (op.cit.) y 2011). La segunda, entre el año 1990 y 1997, en la que por medio de un proceso participativo sustentado en evaluaciones empíricas de las exigencias y de carga de trabajo, la programación de la asignación de los tiempos de conducción y descanso permitió un mayor control de la regulación de la carga de trabajo. La tercera, tras la incorporación de una nueva línea a la red de Metro, marcada por la desarticulación del colectivo histórico de conductores y la desestabilización de los mecanismos regulatorios de la carga de trabajo.

Consistentemente, los antecedentes expuestos en los gráficos 1, 2, 3 y 4, muestran la existencia de variaciones en los niveles globales de acoplamiento de las condiciones de realización de la actividad, al igual que variaciones en el acoplamiento focal entre estas condiciones y las características particulares de los distintos segmentos educacionales de conductores, independientemente del turno de referencia a los que se encontraban asignados.

En un escenario distinto, los procesos vividos en Telefónica Chile, marcados por frecuentes reestructuraciones, fusiones por vía de adquisición de otras empresas, incorporación sucesiva de áreas dedicadas a operar distintos productos del área de las telecomunicaciones y la importante variación en la composición de personal durante el proceso de desarrollo de la organización, han producido significativos efectos sobre la actividad de las personas. A continuación se muestra, a modo de ejemplo, el proceso de constitución de la filial de Telefónica Chile para el desarrollo de la telefonía celular, 
Telefónica Móvil (Díaz Canepa et al., 2001, op.cit.). Los sucesivos cambios vividos por esta organización en sus doce años de existencia al momento del estudio reportado, fueron no sólo definiendo distintos escenarios de actividad, si no que estos fueron vivenciados por composiciones distintas de personal, a la sazón de las distintas cohortes que fueron rotando en la organización (ver figura 6).

Figura 6: Línea histórica, hitos y generaciones de personal en Telefónica Móvil (TM)

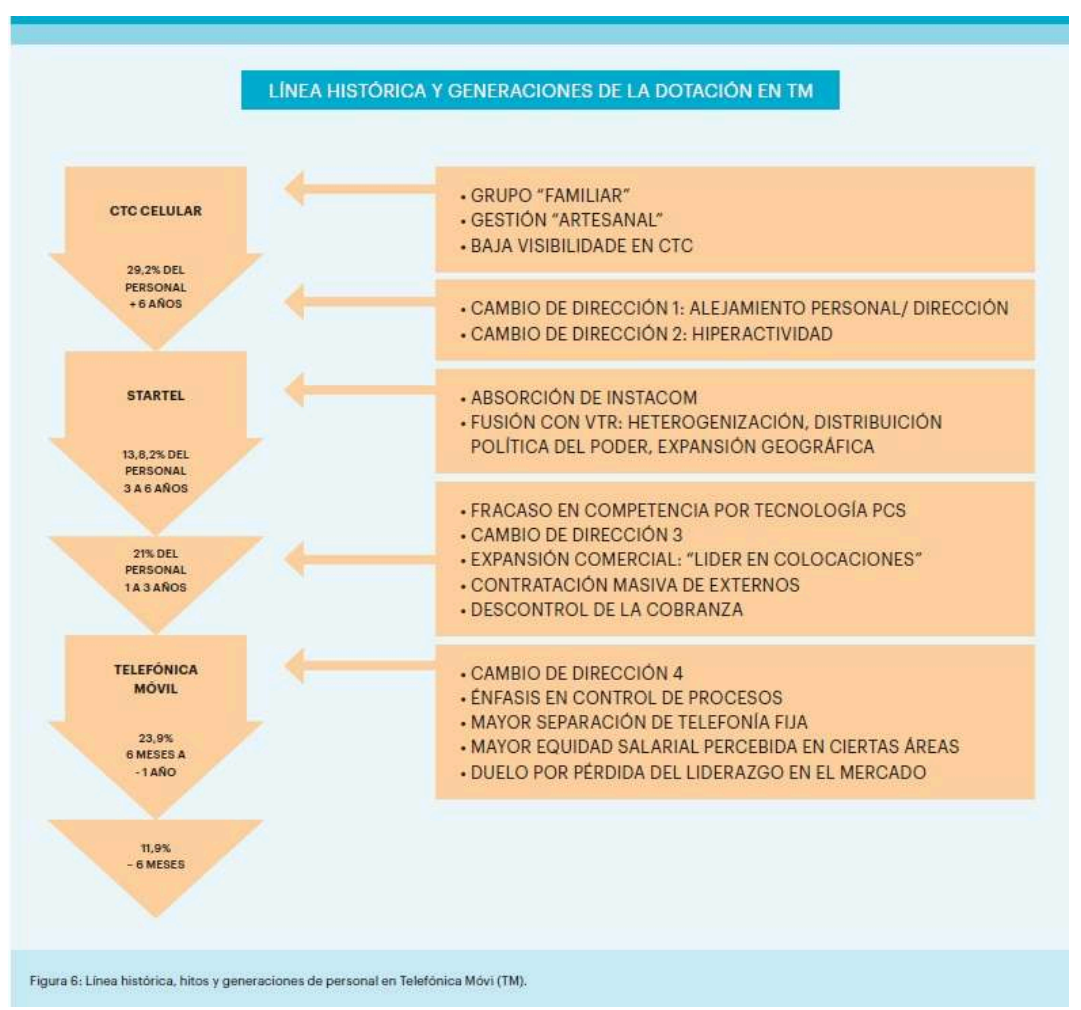

Estos distintos cambios, los que respondían principalmente a lógicas adaptativas a eventos del entorno y a acomodos de los equilibrios de poder interno, fueron generando sucesivos contextos, alimentando la incertidumbre al interior de la organización en cuanto a los lineamientos de la actividad colectiva, traduciéndose en una importante deslegitimación de los mecanismos formales de articulación de la actividad común, y fomentando el correlativo desarrollo de estrategias sustentadas en la creación de redes informales efímeras, operando con criterios casuísticos y de bajo impacto en los resultados sistémicos (Díaz Canepa et al., 2001, op. cit.).

Para hacerse cargo de estos distintos desafíos, es indispensable entonces que el diseño y desarrollo del proceso de cambio, cuente con antecedentes suficientes sobre el comportamiento de las variables sensibles de la situación organizacional, de manera a establecer la forma y orden pertinente de tratamiento en pos de los objetivos del proceso de cambio. Contar con indicadores confiables que permitan hacer seguimiento de los estados de avance de los procesos de cambio, permitirá objetivar el balance situacional y focalizar apropiadamente las acciones a ejecutar. El diseño y puesta en práctica de un modelo operacional de monitoreo es para estos efectos indispensable. En este sentido, si bien existen diversas herramientas propuestas en la literatura y que pueden ser de utilidad en tanto que referentes genéricos para el desarrollo de un modelo de monitoreo, estas propuestas pueden no reflejar necesariamente las 
condiciones relevantes de la situación a intervenir (Khan, Timmings, Moore, Marquez, Pika, Gheihman \& Staruss, , 2014), por lo que es ciertamente recomendable tomar como base preferente aquellas dimensiones que presentan mayor relevancia en el escenario efectivo de intervención. Con este propósito, el desarrollo de un adecuado diagnóstico basado en el análisis de la actividad efectiva y sus subyacentes, resulta ser clave.

\section{Discusión y Conclusiones}

Como se ha señalado en los puntos anteriores, los procesos de cambio revisten diversas dimensiones e interpelan la ocurrencia de variadas dinámicas, las que se presentan a menudo en formas entreveradas y contradictorias, condiciones que hacen de los cambios un proceso a menudo pedregoso, que se desarrolla sustentado en un equilibrio inestable, sujeto a múltiples tensiones y siguiendo ,+

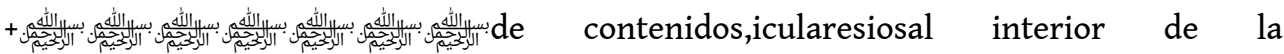
organizaciintos niveles que configuran la organizacique tal como lo señalana menudo trayectorias inesperadas. Es en estas dinámicas donde se instala el riesgo de pérdida de sentido de congruencia de la actividad que realizan las personas, con el consiguiente desarrollo de trayectorias divergentes que atenten contra la articulación del quehacer organizacional.

En efecto, en escenarios donde se instala la incertidumbre en cuanto a lo que tiene sentido hacer y no hacer, si las coordinaciones y definición de roles son insuficientes, o si los nuevos sistemas técnicos no son estables y/o no dan soporte suficiente al desarrollo de las tareas y a la actividad que las personas deben realizar, no resulta muy productivo, por ejemplo, exigir compromiso y apego a las indicaciones operacionales desde una lógica moral o de autoridad, y menos esperar el desarrollo de procesos de apropiación de los cambios por parte de las personas.

Del mismo modo, tal como lo señalan Pettigrew, Goodman \& Cameron (2001), para efectos de enfrentar y gestionar los cambios, entender las dinámicas y efectos del tiempo, de los procesos, de las discontinuidades, así como de los contextos, resulta clave. A lo que agregaríamos, la necesidad de entender igualmente las dinámicas y efectos de las continuidades y equilibrios quasi-estacionarios (Lewin, 1947b, op.cit.), que hacen reconocible el quehacer cotidiano de las organizaciones y dan contorno a las identidades de rol y a las actividades que ejercen las personas al interior de la organización.

Dadas esas situaciones, gestionar el cambio atendiendo a resguardar las condiciones que sostengan el sentido de la actividad, necesariamente requiere de una mirada multidimensional, multinivel (Whelan-Berry, et al, op.cit., 2003) y un esfuerzo inicial de ordenamiento de la relevancia y de la temporalidad del tratamiento a dar a los factores que concurren a la situación, articulado a partir del sentido de propósito de la actividad desplegada por las personas.

Este ordenamiento debiera permitir dar un curso reconocible al proceso de cambio y un soporte para la focalización de las acciones a desplegar. Importa entonces rescatar una lógica de sentido, en la que los cambios den cuenta de propósitos reconocibles y legítimos para los miembros de la organización, tanto en sus contenidos, como en su forma de realización. 
91 Vale la pena enfatizar que el sentido no sólo se soporta en la racionalidad y razonabilidad de los cambios, sino que también toma pie en el sustrato subjetivo y emocional con que cuenta la organización (Armenakis, Bernerth, Pitts \& Walker, 2007; Andrews, et al., 2008). Para ello es clave reconocer la(s) cultura(s) presentes en la organización, pues los cambios para arraigarse y sustentarse, requieren tomar base en el hilo conductor de significados que la cultura de la organización proporciona, proyectándolos o resignificándolos. Por lo tanto, parece razonable orientar las estrategias preferentemente hacia el desarrollo de procesos de apropiación de lo nuevo, más que hacia una lógica de reducción o control de las resistencias.

Desde esta óptica, y asumiendo que la denominada "resistencia al cambio" es de naturaleza multidimensional (Smollan, 2011), es necesario considerar que mientras más radicales sean los cambios, que estos presenten importantes grados de discontinuidad, afectando las prácticas con las que se desarrolla la actividad y/o la situación de personas, prestar atención a la forma en que se realicen los cambios y el modo como se incorpore a las personas en dicho proceso, adquiere sin lugar a dudas una mayor relevancia.

93 La actividad, en tanto que proceso situado (Rogoff \& Lave, 2000) y dirigido a metas (Bedny et al., 1997 (op. cit)) requiere contar con marcos referenciales reconocibles para desarrollarse en forma apropiada, resguardando el equilibrio entre los objetivos organizacionales y de las personas. Este es por lo tanto uno de los principales desafíos a enfrentar en los procesos de cambio, por lo que importa ir estableciendo hitos operacionalmente visibles y soportes de acompañamiento que permitan a la vez, reducir el campo de incertidumbres y canalizar convergente y significativamente la actividad de los miembros de la organización hacia crecientes procesos de apropiación de lo nuevo, con base a dinámicas de aprendizaje expansivo (Engeström, 1987 (op. cit.), 1999 (op. cit.)), soportado desde los recursos de experiencia, competencias y sociales con que cuentan las personas.

Del mismo modo, lograr el ajuste entre los recursos disponibles materiales y tecnológicos disponibles, las estructuras organizacionales, prescripciones y roles funcionales, dado su incidencia en tanto que mediadores de la actividad, resulta ser crítico para resguardar el logro de niveles de convergencia entre los distintos niveles que configuran la organización, facilitando el desarrollo de procesos de construcción de sentido que permitan el despliegue armónico de la actividad de las personas y de los colectivos de los que estas hagan parte.

95 Atendiendo a las complejidades ya enunciadas, al momento de proponerse la realización de un cambio, es de utilidad explicitar las respuestas a algunas preguntas relevantes: ¿Por qué cambiar? ¿Cuál es el estado deseado al que se aspira? ¿Qué cambiar y qué se espera mantener? ¿Qué efectos tendrá eventualmente sobre la actividad de las personas? ¿Qué articulaciones se debilitan y cuáles nuevas articulaciones será necesario definir y sostener? ¿Qué continuidades y cuáles quiebres son posible de visualizar? ¿Qué efectos tendrá sobre la situación de las personas? ¿Qué costos se pueden y/o se quieren asumir? ¿Cuál es el balance esperable de costos-beneficios del proceso de cambio en razón de las condiciones en que se realizaría y los resultados esperados? ¿Se disponen de recursos y herramientas que permitan emprender adecuadamente el proceso de cambio? Las respuestas a estas preguntas darán ciertamente luces con respecto a las prioridades y capacidades efectivas que subyacen a la intención de 
cambio, así como en relación a las trayectorias que aparezcan como eventualmente disponibles y viables a transitar.

En definitiva y a modo de conclusión provisoria, podríamos decir que la compleja articulación de los aspectos técnicos, subjetivos, pragmáticos y contextuales implicados en los procesos de cambio, supone un delicado y triple equilibrio. Primero, entre la indispensable integración y participación pertinente de las personas que se verán afectadas en alguna medida por los cambios y una lógica de conducción centralizada, que permita darle direccionalidad y una impronta consistente al proceso. Segundo, entre los recursos organizacionales dispuestos para que las personas puedan operar congruentemente las acciones que requieren los cambios, y las indicaciones y exigencias que se les hace desde sus jefaturas para efectos de operar dichos cambios. Tercero, entre los requerimientos de continuidad y de asimilación de lo nuevo a las prácticas y recursos vigentes, versus los requerimientos de cambio, acomodación y apropiación de nuevas prácticas. Es en estos equilibrios donde entendemos se juega gran parte la mantención y proyección del sentido que las personas le otorgan a la actividad que realizan, y por ende a la efectiva expansión de la actividad desarrollada, así como de las posibilidades de éxito de los cambios implementados.

\section{BIBLIOGRAFÍA}

Aldrich, H. (1979). Organizations and environments. NJ: Prentice Hall. Englewood Cliffs.

Andrews, J., Cameron, H. \& Harris, M. (2008). All change? Managers' experience of organitazional change in theory and practice. Journal of Organizational Change Management, 21, 3, 300-314.

Armenakis, A., Bernerth, J., Pitts, J. P. \& Walker, H. J. (2007). Organizational change recipients' beliefs scale development of an assessment instrument. The Journal of Applied Behavioral Science, $43,4,481-505$.

Batteau, A. W. (2000). Negations and ambiguities in the cultures of organization. American Anthropologist, New Series, 102, 4, 726-740.

Bedny, G., \& Meister, D. (1997). The Russian theory of activity. New Jersey: Lawrence Erlbaum Associates.

Beer, M., \& Nohria, N. (2000). Breaking the code of change. Boston: Harvard Business School Press. Bridges, W. (1991). Managing Transitions. MA: Addison-Wesley Reading.

Boga, I., \& Ensari, N. (2009). The role of transformational leadership and organizational change on perceived organizational success. The Psychologist-Manager Journal, 12, 235-251.

Brunsson, N. (1982). The irrationality of action and action rationality: decisions, ideologies, and organizational actions. Journal of Management Studies, 19, 29-34.

Bryant, M. \& Frahm, J. (2011). 'Kill Bill' and the change agent: a multi-genre approach to organizational stories. Journal of Management \& Organization, 17, 797-811.

Burke, W. W. (2008). Organization change: theory and practice. CA: Sage Publications Inc. 
Campbell, D. (1969). Variation and selective retention in socio-cultural evolution. General systems, $16,69-85$

Clot, Y. (1999). La fonction psychologique du travail. Paris: PUF.

Commons, J. R. (1950). The economics of collective action. Madison: University of Wisconsin Press.

Danisman, A. (2010). Good intentions and failed implementations: Understanding culture-based resistance to organizational change. European Journal of Work and Organizational Psychology, 19, 2, 200-220.

Davis, K. Y., \& Newstrom, J. (1991). Comportamiento humano en el trabajo: comportamiento organizacional. Mexico: McGraw-Hill/Interamericana de Mexico S.A.

Demers, Ch. (2007). Organizational change theories: a synthesis. CA: Sage Publications Inc.

Denis, J. L., Lamothe, L. \& Langley, A. (1996). The dynamics of collective leadership and strategic change in pluralistic organizations. Academy of Management Journal, 44, 4, 809-838.

Dent, E., \& Galloway, S. (1999). Challenging resistance to change. Journal of Applied Behavioral Science, 35, 1, 25-41.

Detert, J. R., Schhroeder, R. G. \& Mauriel, J. J. (2000). A framework for linking culture and improvement initiatives in organizations. Academy of Management Review, 25, 850-863.

Devos, G., Buelens M., \& Bouckenooghe, D. (2007). Contribution of content, context, and process to understanding openness to organizational change: two experimental simulation studies. The Journal of Social Psychology, 147, 6, 607-629.

Díaz Canepa, C., Cox Undurraga, J., Bilbao Ramirez, M. \& Valdivia Lopez, V. (2001). Estudio de cultura organizacional y delimitaciones de factores de clima laboral Empresa Telefónica Móvil. Monografía EPUC. Santiago de Chile.

Díaz Canepa, C., Poblete, M., \& Torres, B. (2005). Proyecto de acción sobre el clima laboral con base en la cultura organizacional de casa matriz de ENAP. Informe de Consultoría, CIDEM. Santiago de Chile.

Díaz Canepa, C. (2005) Transferring technologies to developing countries: a cognitive and cultural approach in Robert J. Sternberg \& David C. Preiss (Eds.) Intelligence \& Technology (pp.xx-xx). New Jersey: Lawrence Erelbaum.

Díaz Canepa, C., Berkovich, N., \& Preiss, D. (2006). Sistemas y prácticas de trabajo: Gerencia Técnica deTelefónica Empresas. Informe de estudio, PUC, Santiago de Chile.

Díaz Canepa, C. (2007). Influencia de las socializaciones previas y trayectorias biográficas sobre la constitución de rol y comportamiento laboral en conductores de metro. Tesis presentada para optar al grado de Doctor en Psicología. Santiago de Chile: Facultad de Ciencias Sociales, Universidad de Chile.

Díaz Canepa, C. (2008a). Organizaciones flexibles, incertidumbre e identidad. In A. Soto Roy, Flexibilidad Laboral y Subjetividades (pp.177-190). Santiago de Chile: LOM.

Díaz Canepa, C. (2008b). Actividad, contexto organizacional y competencias. Revista Psicología Organizacional Humana, 1, 2, 54-68.

Díaz Canepa, C. (2011). Dinámicas organizacionales de producción incremental de carga de trabajo: influencia de los roles, reglas y artefactos en la articulación de la actividad laboral. Laboreal, 7, 2, 25-38. http://laboreal.up.pt/revista/artigo.php?id=37t45n SU547112435:263944761 Díaz Canepa, C., Arancibia D., \& Drobny, T. (2015). Informe técnico GCO-Abril. Informe interno Equipo Gestión del Cambio, Hospital de la Florida, Santiago de Chile. 
Dos Santos Paulino, V. (2009). Organizational change in risky environments: space activities. Journal of Organizational Change Management, 22, 3, 257-274.

Dooley, K., \& Van de Ven, A. (1999). Explaining complex organizational dynamics. Organization Science, 10, 3, Special Issue: Application of Complexity Theory to Organization Science, 358-372.

Duck, J. D. (2005). Gestionar el cambio en gestión del cambio. Santiago de Chile: Harvard Bussines Review, Ed. Planeta Chilena.

Engeström, Y. (1987). Learning by expanding. An activity-theoretical approach to developmental research. Helsinki: Orienta Konsultit Oy.

Engeström, Y. (1999). Activity theory and individual and social transformation. In Y. Engeström, R. Meiettinen, \& R-L Punamäki, Perspectives on activity theory (pp.19-38). Cambridge: Cambridge University Press.

Erickson, F., \& Schultz, J. (1997). When is a context? Some issues in the analysis of social competence. In M. Cole, Y. Engeström, \& O. Vasquez, (Eds.), Mind, Culture and Activity (pp.22-31), Cambridge: Cambridge University Press.

Fugate, M., Kinicki, A. J., \& Prussia, G. E. (2008). Employee coping with organizational change: an examination of alternative theoretical perspectives and models. Personnel Psychology, 61, 1-36.

Geertz, C. (1973). The interpretation of cultures: selected essays. N.Y.: Basic Books.

Gibson, E. J. (1988). Exploratory behavior in the development of perceiving, acting, and the acquiring of knowledge. Annual Review of Psychology, 39, 1-41.

Gladwell, M. (2000). The tipping point: how little things can make a big difference. London: Little Brown and Co.

Golembiewski, R.T. (1986). Contours in social change: elemental graphics and a surrogate variable for gamma change. The Academy of Management Review, 11, 3, 550-566.

Hannan, M. T., \& Freeman, F. (1977). The population ecology of organizations. American Journal of Sociology, 82, 929-964.

Hannan, M.T., \& Freeman, F. (1989). Organizational ecology. Cambridge MA: Harvard University Press.

Hannan, M.T., Pólos L., \& Carroll, G.R. (2003). Cascading organizational change. Organization Science, $14,5,463-482$.

Hatchuel A. (1996). Coopération et conception collective. Variété et crises des rapports de prescription, in G. De Terssac \& E., Friedberg, Coopération et conception, (pp.101-121), Toulouse: Octarès.

Hoogendoorn. M, Jonker, C., Schut, M., \& Treur, J. (2007). Modeling centralized organization of organizational change. Comput Math Organiz Theor, 13,147-184

Holt, D.T., Helfrich, C.D., Hall, C.G. \& Weiner, B.J. (2010). Are you ready? How health professionals can comprehensively conceptualize readiness for change. J Gen Intern Med, 25, 1, 50-55.

Jimmieson, N., Peach, M., \& White, K. (2008). Utilizing the theory of planned behavior to inform change management: an investigation of employee intentions to support organizational change. The journal of applied behavioral science, 44, 2, 237-262.

Jermier, J. M., Knights, D., \& Nord, W. R. (Eds.). (1994). Resistance and power in organizations. London: Routledge. 
Kanter, R. M. (1988). When a thousand flowers bloom: structural, collective, and social conditions for innovation in organization. In B. M. Staw \& L. L. Cummings (Eds.), Research in organizational behavior Vol. 10, (pp. 169-211). Greenwich, CT: JAI Press.

Khan, S., Timmings, C., Moore, J., Marquez, C., Pika, K., Gheihman, G. \& Staruss, Sh. (2014). The development of an online decision support tool for organizational readiness for change. Implementation Science, 9, 56. DOI: 10.1186/1748-5908-9-56

Kiefer, T. (2005). Feeling bad: antecedents and consequences of negative emotions in ongoing change", Journal of Organizational Behavior, 26, 875-97.

Kotter, J. P. (2005). Liderar el cambio en Gestión del cambio. Santiago de Chile: Harvard Bussines Review, Ed. Planeta Chilena.

Krantz, J. (1999). Comment on "challenging 'resistance to change." Journal of Applied Behavioral Sciences, 35, 1, 42-44.

Kuutti, K. (2001). Activity theory as a potential framework for human-computer interaction research in B. Nardi, (Ed.), Context and consciousness (pp.17-44). Cambridge: MIT Press.

Lazarus, R. S. (1991). Cognition and motivation in emotion. American Psychologist, 46, 352-367.

Leonardi, P.M. (2007). Activating the informational capabilities of information technologies for organizational change. Organization Science, 18, 5, 813-831.

Leplat J. (1997). Regards sur l'activité en situation de travail. Contribution à la psychologie ergonomique. Paris: PUF.

Leplat, J (2004). L'analyse psychologique du travail. Revue Européene de psychologie appliquée, 54, 101-108.

Lewin, K. (1947a). Frontiers in group dynamics. Human Relations, 1, 5-41.

Lewin, K. (1947b). Quasi-stationary social equilibria and the problem of permanent change in W. Burke, D. Lake, \& J. Paine, (2009).Organization change: A comprehensive reader. San Francisco: CA Jossey-Bass.

Lewin, K. (1952). Field theory in social science: Selected theoretical papers. London: Cartwrigth D. Ed., Tavistock Publications Ltd.,

Mack. D.A., Nelson, D.L. \& Campbell-Quick, J. (1998). The stress of organizational change: a dynamic process model. Applied Psychology: An International Review, 47, 2, 219-232.

Marks, M.L. (2003). Charging back up the hill: workplace recovery after mergers, acquisitions, and downsizings. San Francisco, CA: Jossey-Bass.

Marks, L.M. (2007). A framework for facilitating adaptation to organizational transition. Journal of Organizational Change Management, 20, 5, 721-739.

Martin, J. (2002). Organizational culture. Thousand Oaks: Sage Publications.

Miettinen, R., \& Virkkunen, J. (2005). Epistemic objects, artefacts and organizational change. Organization, 12, 3, 437-456.

Morel. B., \& Ramanujam, R. (1999). Through the looking glass of complexity: the dynamics of organizations as adaptive and evolving systems. Organization Science, 10, 3, Special Issue: Application of Complexity Theory to Organization Science, 278-293.

Nathanael, D., \& Marmaras, N. (2008). On the development of work practices: a constructivist model, Theoretical Issues in Ergonomics Science, 9, 5, 359 -382. 
Neal, M. A., \& Northcraft, G. B. (1991). Behavioral negotiation theory: a framework for conceptualizing dyadic bargaining. In L. L. Cummings \& B. M. Staw (Eds.), Research in organizational behavior, vol. 13 (147-190). Greenwich, CT: JAI Press.

Nelissen, P., \& Van Selm, M. (2008). Surviving organizational change: how management communication helps balance mixed feelings. Corporate Communications: An International Journal, 13, 3, 306-318.

Pettigrew, A., Goodman, R. \& Cameron, K. (2001). Studying organizational change and development challenges for future research. Academy of Management Journal ${ }_{44,4}, 697-713$.

Piderit, S. K. (2000). Rethinking resistance and recognizing ambivalence: a multidimensional view of attitudes toward an organizational change. The Academy of Management Review, 25, 4, 783-794.

Pina, M., \& Vieira. J. (2003). Organizational improvisation and change: two syntheses and a filled gap. Journal of Organizational Change Management, 16, 2, 169-184.

Rabardel, P. (1995). Les hommes et les technologies: approche cognitive des instruments contemporains. Paris: Armand Colin.

Rodríguez, D. (1992). Diagnóstico organizacional. Santiago: Ediciones Universidad Católica de Chile. Rogoff, B., \& Lave J. (ed.) (2000). Everyday cognition, its development in social context. N.J.: Harvard University Press.

Roscigno, V., \& Hodson, R. (2004). The Organizational and social foundations of worker resistance. American Sociological Review, 69, 1, 14-39.

Schein, E.H. (1992). Organizational culture and leadership. San Francisco, CA: Jossey-Bass Publishers. Schein, E.H. (1996). Culture: the missing concept in organization studies. Administrative Science Quarterly, 41, 2, 229-240.

Smollan, R. K. (2011). The multi-dimensional nature of resistance to change. Journal of Management \& Organization, 17, 828-849.

Soparnot, R. (2011). The concept of organizational change capacity. Journal of Organizational Change Management, 24, 5, 640-661.

Stensaker, I., Falkenberg, J., Meyer, Ch., \& Hagueng, A. (2002). Excessive change: coping mechanisms and consequences. Organizacional Dynamics, 31, 3, 296-312.

Strebel, P, (2005). ¿Por qué los empleados se resisten al cambio? en Gestión del cambio. Santiago de Chile: Harvard Bussines Review, Ed. Planeta Chilena.

Terssac de, G. (1990). La polyvalence redéfinie par les intéressés. In M. Dadoy, C.Henry, B. Hillau, G. de Terssac, J.-F. Troussier \& A. Weil-Fassina, Les analyses du travail, enjeux et formes, (pp. 34). Paris: Cereq.

Terssac de, G., \& Chabaud C. (1990). Référentiel opératif commun et fiabilité. In J. Leplat, G. de Terssac, Les facteurs humains de la fiabilité dans les systèmes complexes, (pp. 111-139). Toulouse: Octarès.

Theureau J. (2001) La notion de charge mentale est-elle soluble dans l'analyse du travail et la conception ergonomiques, Conférence introductive aux Journées Act'ing/Ergonomia, Cassis.

Thévenet, M. (1988). Plus c'est la même chose, plus ça change. Revue française de gestion, 68, 89-92. Trompenaars, F. (1993). Riding the waves of culture: Understanding cultural diversity in business. London: Nicholas Brealey. 
Tsoukas, H., \& Chia, R. (2002). On organizational becoming: rethinking organizational change. Organization Science, 13, 5, 567-582.

Vakola, M., \& Nikolaou, I. (2005). Attitudes towards organizational change: what's the role of employees' stress and commitment? Employee Relations, 27, 160-174.

Van Emmerik, I.J.H., Bakker, A.B., \& Euwema, M.C. (2009). Explaining employees' evaluations of organizational change with the job-demands resources model. Career Development International, 14, 6, 594-613.

Van de Ven, ${ }^{\text {A.H. }}$ \& Poole, M.S. (1995). Explaining development and change in organizations. Academy of Management Review, 20, 510-540

Watson, T. J. (1982). Group ideologies and organizational change. Journal of Management Studies, $19,259-275$.

Watzlawick, P., Weakland, J., \& Fisch. R. (1974). Change: principles of problem formation and problem resolution. N.Y.: W. W. Norton \& Company,

Weber, M. (1964) Economía y sociedad: esbozo de sociología comprensiva. Mexico: Fondo De Cultura Económica.

Whelan-Berry, Karen S., Gordon, Judith R., \& Hinings, C. R. (2003). Strengthening organizational change processes: recommendations and implications from a multilevel analysis. The Journal of Applied Behavioral Science, 39, 2, 186-207.

Weick, K.E., \& Quinn, R.E. (1999). Organization change and development. Annual Review of Psychology, 50, 361-86.

\section{NOTAS}

1. La palabra afordancia es un neologismo derivado del inglés, affordance, y refiere a las características de un artefacto o situación, en cuanto al grado en que posibiliten la acción propositiva de las personas.

\section{RESÚMENES}

Las organizaciones tienden a la creación y permanencia de rutinas que hacen predecible su quehacer. Los cambios en las organizaciones introducen efectos a menudo inesperados, incrementando la incertidumbre y la casuística operacional, afectando a las personas y la forma en que se realiza la actividad. La literatura en torno al cambio organizacional privilegia el análisis de los factores que subyacen a los procesos de cambio, incluyendo el rol de la actividad propositiva de los miembros de la organización (agency), no obstante, poco abordan los efectos que estos cambios generan sobre la actividad concreta de los actores organizacionales. Se examinan enfoques y tópicos relevantes respecto a los procesos de cambio organizacional y sus efectos sobre la actividad y las personas. 
As organizações tendem a criar e manter rotinas que possibilitam o seu funcionamento previsível. As mudanças introduzidas nas organizações, muitas vezes geram efeitos inesperados, aumentando a incerteza e a casuística operacional, que afetam as pessoas e a forma como a atividade é realizada. A literatura sobre a mudança organizacional favorece a análise dos fatores subjacentes aos processos de mudança, incluindo o papel da atividade propositiva de membros da organização (agency), no entanto, pouco aborda sobre os efeitos dessas mudanças na atividade concreta dos atores organizacionais. Neste estudo são analisados enfoques e temáticas relevantes sobre os processos de mudança organizacional e seus efeitos sobre a atividade e as pessoas.

Les organisations ont tendance à la création et à l'entretien de routines qui rendent leur fonctionnement prévisible. Les changements introduits dans les organisations ont souvent des effets inattendus, causant l'augmentation de l'incertitude et de la casuistique opérationnelle, affectant les personnes et la façon dont l'activité est réalisée. La littérature sur le changement organisationnel favorise l'analyse des facteurs sous-jacents des processus de changement, y compris le rôle de l'activité propositive des membres de l'organisation (agency). Cependant, ils n'abordent que brièvement les effets que ces changements génèrent sur l'activité spécifique des acteurs organisationnels. Sont examinés dans ce papier les approches et les thématiques en relation avec les processus de changement organisationnel et ses effets sur l'activité et les personnes.

Organizations tend to create and hold routines that make their work predictable. Changes in organizations often introduced unexpected effects, increasing uncertainty and operational casuistry, affecting people and their activity. The literature on organizational change favors the analysis of factors underlying the change processes, including the role of purposive activity of members of the organization (agency), however, shortly address the effects these changes generate about the specific activity of organizational actors.

Relevant topics are discussed regarding change processes, and effects they entail on people and their performed activities.

\section{ÍNDICE}

Mots-clés: activité, changement, gestion du changement

Palabras claves: organizaciones, actividad, cambio, gestión del cambio

Keywords: organizations, activity, change, change management

Palavras-chave: organizações, atividade, mudança, gestão da mudança

\section{AUTOR}

\section{CARLOS DÍAZ CANEPA}

Departamento de Psicología, Facultad de Ciencias Sociales, Universidad de Chile, Capitán Ignacio Carrera Pinto 1045, Ñuñoa, Santiago de Chile - Chile, Código postal: 7800284

carldiaz@uchile.cl 